\title{
Integral sentences and numerical comparative calculations for the validity of the dispersion model for air pollutants AUSTAL2000
}

Rainer Schenk ${ }^{1,2^{*}}$ (1)

\begin{abstract}
Background: The authors (Janicke and Janicke (2002). Development of a model-based assessment system for machine-related immission control. IB Janicke Dunum) developed an expansion model under the name AUSTAL2000. This becomes effective in the Federal Republic of Germany with the entry into force of TA Luft (BMU (2002) First general administrative regulation for the Federal Immission Control Act (technical instructions for keeping air TA air clean) from July 24, 2002. GMBL issue 25-29 S: 511-605) declared binding in 2002. Immediately after publication, the first doubts about the validity of the reference solutions are raised in individual cases. The author of this article, for example, is asked by senior employees of the immission control to express their opinions. However, questions regarding clarification in the engineering office Janicke in Dunum remain unanswered. In 2014, the author of this article was again questioned by interested environmental engineers about the validity of the reference solutions of the AUSTAL dispersion model. In the course of a clarification, the company WESTKALK, United Warstein Limestone Industry, later placed an order to develop expertise on this model development, Schenk (2014) Expertise on Austal 2000. Report on behalf of the United Warstein Limestone Industry, Westkalk Archives and IBS). The results of this expertise form the background of all publications on the criticism of Schenk's AUSTAL expansion model. It is found that all reference solutions violate all main and conservation laws. Peculiar terms used spread confusion rather than enlightenment. For example, one confuses process engineering homogenization with diffusion. When homogenizing, one notices strange vibrations at the range limits, which cannot be explained further. It remains uncertain whether this is due to numerical instabilities. However, it is itself stated that in some cases the solutions cannot converge. The simulations should then be repeated with different input parameters. Concentrations are calculated inside AUSTAL. In this context, it is noteworthy that no publication by the AUSTAL authors specifies functional analysis, e.g. for stability, convergence and consistency. Concentrations are calculated inside closed buildings. It is explained that dust particles cannot "see" vertical walls and therefore want to pass through them. One calculates with "volume sources over the entire computing area". However, such sources are unknown in the theory of modeling the spread of air pollutants. Deposition speeds are defined at will. 3D wind fields should be used for validation. The rigid rotation of a solid in the plane is actually used. You not only deliver yourself, but also all co-authors and official technical supporters of the comedy. Diffusion tensors are formulated without demonstrating that their coordinates have to comply with the laws of transformation and cannot be chosen arbitrarily. Constant concentration distributions only occur when there are no "external forces". It is obviously not known that the relevant model equations are mass balances and not force equations. AUSTAL
\end{abstract}

\footnotetext{
*Correspondence: ibswettin@web.de

1 Present Address: 06193 Wettin-Löbejün, Germany

Full list of author information is available at the end of the article
} 
also claims to be able to perform non-stationary simulations. One pretends to have calculated time series. However, it is not possible to find out in all reports which time-dependent analytical solution the algorithm could have been validated with. A three-dimensional control room is described, but only zero and one-dimensional solutions are given. All reference examples with "volume source distributed over the entire computing area" turn out to be useless trivial cases. The AUSTAL authors believe that "a linear combination of two wind fields results in a valid wind field". Obviously, one does not know that wind fields are only described by second-degree momentum equations, which excludes any linear combinations. It is claimed that Berljand profiles have been recalculated. In fact, one doesn't care about three-dimensional concentration distributions. On the one hand, non-stationary tasks are described, but only stationary solutions are discussed. In another reference, non-stationary solutions are explained in reverse, but only stationary model equations are considered. Further contradictions can be found in the original literature by the AUSTAL authors. The public is misled. The aim of the present work is to untangle the absent-mindedness of the AUSTAL authors by means of mathematics and mechanics, to collect, to order and to systematize the information. This specifies the relevant tasks for the derivation of stationary and non-stationary reference solutions. They can be compared to the solutions of the AUSTAL authors. These results should make it possible to make clear conclusions about the validity of the AUSTAL model.

Results: Using the example of deriving reference solutions for spreading, sedimentation and deposition, the author of this work describes the necessary mathematical and physical principles. This includes the differential equations for stationary and non-stationary tasks as well as the relevant initial and boundary conditions. The valid initial boundary value task is explained. The correct solutions are given and compared to the wrong algorithms of the AUSTAL authors. In order to check the validity of the main and conservation laws, integral equations are developed, which are subsequently applied to all solutions. Numerical comparative calculations are used to check non-stationary solutions, for which an algorithm is independently developed. The analogy to the impulse, heat and mass transport is also used to analyze the reference solutions of the AUSTAL authors. If one follows this analogy, all reference solutions by the AUSTAL authors comparatively violate Newton's 3rd axiom. As a result, the author of this article comes to the conclusion that all reference solutions by the AUSTAL authors violate the mass conservation law. Earlier statements on this are confirmed and substantiated further. All applications with "volume source distributed over the entire computing area" turn out to be useless zero-dimensional trivial cases. The information provided by the AUSTAL authors on non-stationary solutions has not been documented throughout. The authors of AUSTAL have readers puzzled about why, for example, the stationary solution should have set in after 10 days for each reference case. It turns out that no non-stationary calculations could be carried out at all. In order to gain in-depth knowledge of the development of AUSTAL, the author of this article deals with his life story. It begins according to (Axenfeld et al. (1984) Development of a model for the calculation of dust precipitation. Environmental research plan of the Federal Minister of the Interior for Air Pollution Control, research report 10402 562, Dornier System GmbH Friedrichshafen, on behalf of the Federal Environment Agency), according to which one is under deposition loss and not Storage understands. In the end, the AUSTAL authors take refuge in (Trukenmüller (2016) equivalence of the reference solutions from Schenk and Janicke. Treatise Umweltbundesamt Dessau-Rosslau S: 1-5) in incomprehensible evidence. How Trukenmüller gets more and more involved in contradictions can be found in (Trukenmüller (2017) Treatises of the Federal Environment Agency from February 10th, 2017 and March 23rd, 2017. Dessau-Rosslau S: 1-15).

Conclusion: The author of this article comes to the conclusion that the dispersion model for air pollutants AUSTAL is not validated. Dispersion calculations for sedimentation and depositions cannot be carried out with this model. The authors of AUSTAL have to demonstrate how one can recalculate nature experiments with a dispersion model that contradicts all valid principles. Applications important for health and safety, e.g. Security analyzes, hazard prevention plans and immission forecasts are to be checked with physically based model developments. Court decisions are also affected.

Keywords: AUSTAL2000, Dispersion calculations, Particle model, Sedimentation, Deposition, Air pollutants

\section{Background}

By the authors Janicke et al. (2002) a dispersion model is developed under the name AUSTAL2000. In the Federal Republic of Germany, this became binding in 2002 when the Technical Instructions for Air Quality Control (TA
Luft), BMU (2002), came into force. Other model developments have to prove their equivalence to the reference solutions of AUSTAL. Immediately after publication, individual employees of immission control and later also environmental engineers raise doubts about the validity 
of the reference solutions. For the purpose of clarification, the author of this article in 2014 was commissioned by the company WESTKALK, United Warstein Limestone Industry, to develop expertise on this expansion model according to Schenk (2014). The author of this article comes to the conclusion that all reference solutions from AUSTAL violate mass conservation and the second law of thermodynamics and are therefore not usable. The use of critical terms also leads to the conclusion that the AUSTAL authors are not very familiar with the theory of modeling the spread of air pollutants. The results of this expertise are published in Schenk (2015a). They form the background of all criticism. In Trukenmüller et al. (2015) is strongly contradicted. However, the authors of this publication are forced to publish the derivation of their reference solutions for the first time in 31 years. The development of the AUSTAL dispersion model is based on the work of Axenfeld et al. (1984). 31 years had passed until 2015. In the solution process of the reference solutions one refers to an alleged "usual Convention", which could be found everywhere in "listed standard literature". With this convention, which is later referred to as the Janicke Convention, the speed of deposition is mistakenly understood as a proportionality factor and not as a material constant. The following replica Schenk (2015b) demonstrates that the one described in Trukenmüller et al. (2015) specified algorithm is incorrect. The initial boundary value tasks responsible for spreading, sedimentation and deposition cannot be solved without contradiction. The authors resist again and claim in Trukenmüller (2016) that there is equivalence to the correct solutions described in Schenk (2015b). The author of this article is clearly against this claim. It is not credible that this claim can only be traced back to ignorance. It is more likely that one is pursuing an intention to deceive here, as will be understood later. For example, the claim that Venkatram et al. (1999) also proves to be devoid of purpose. The publication Schenk (2017) proves that it is solely an unfounded evidence. In Trukenmüller (2017) i.a. tried again to save Janicke's Convention. One almost conjures up the author of this article that he should "... recognize the correct boundary condition, and this follows from the definition of the deposition speed". It simply "... parameterizes the mass balance at the bottom of the model...", which actually leads to a loss of mass, as was already the case in Axenfeld et al. (1984) must admit. "Worldwide, the dispersion models are based on the definition of the speed of deposition that is recognized in the literature", you can read. However, studying literature has shown that the opposite is correct. You obviously only use the reputation of authorities to distract yourself from your ignorance. This allegation will also be justified later. Because of the demand for equivalence of other model developments to AUSTAL, non-university research is blocked rather than promoted. How should new model developments be able to demonstrate equivalence if the necessary reference solutions contradict all principles of mathematics and mechanics. The Schenk publication (2018a) shows which faults the demand for equivalence leads to. Not only is the AUSTAL dispersion model not validated. The authors of other model developments are forced to question their excellent algorithms, e.g. can be found in Schorling (2009). Finally, Schenk (2018b) proves, for example, that the authors of AUSTAL have compared the results of Venkatram et al. (1999) understand deposition as loss rather than storage. All incantations in Trukenmüller (2017) are questioned. At the request of authorities and other interested parties, the AUSTAL authors are currently spreading the Trukenmüller (2016) deception regarding the validity of the AUSTAL expansion model. They don't care that this already contradicts Trukenmüller (2017). Because once Trukenmüller denies al al. (2015) the correctness of the solutions according to Schenk (2015a). And another time, Trukenmüller (2016) wants to demonstrate equivalence to it. The public is confused and misled. The aim of the present work is to untangle this embarrassment of the AUSTAL authors. For this purpose, all information provided by the AUSTAL authors in all available publications is collated, arranged and systematized. Optionally, stationary and non-stationary tasks are considered and the associated solutions are described. They can be compared to the solutions of the AUSTAL authors. Integral rates for mass balance and numerical comparative calculations are used for this. It turns out that all of Schenk's criticism of the AUSTAL expansion model is justified and cannot be invalidated.

In Sect. "Methods and material" of this work an overview of the contents of the literature used is given. The author of this article studies past and current literature by the AUSTAL authors. The basic knowledge of mathematics and mechanics is described in textbooks and monographs. The fact that Trukenmüller (2016) is intended to deceive is deepened. The accusation that Trukenmüller (2017) tries to distract from one's own ignorance and uses the reputation of other authors is justified. Section "Berljand's boundary condition, initial boundary value problem and integral theorems" provides the mathematical and physical foundations for deriving, analyzing and evaluating AUSTAL's reference solutions. This includes the derivation of the boundary conditions valid for spreading, sedimentation and deposition, the description of the relevant model equations as well as the development of integral sentences for the establishment of mass balances. A comparison of the contradictory solutions of the author of this article with the wrong 
algorithms is made in Sect. "Calculation of concentration, sedimentation and deposition for a one-dimensional spread of air pollutants". This section also explains how the Janicke Convention was created and used. It is differentially emphasized that their use leads to a mass deficit. In Sect. "Reference solutions for dispersion, deposition, sedimentation and homogeneity" the contradictory and wrong solutions are optionally given for stationary and non-stationary considerations for all reference cases for dispersion, sedimentation, deposition and homogeneity. Their validity is checked using the developed integral rates. The reference solutions of the AUSTAL authors comparatively contradict Newton's 3rd axiom. This statement is made in Sect. "The analogy to the impulse, heat and mass transfer". How can it happen that the AUSTAL expansion model has been misleading the public from 1984 to the present? The author of this article deals with this question in Sect. "The life stories of the AUSTAL dispersion model".

\section{Methods and material}

In the present case, it should be checked on the basis of generally valid integral sentences for each individual case of the reference solutions of the dispersion model AUSTAL whether the mass conservation law or the II. Law of thermodynamics are violated. It is also necessary to clarify how stationary and non-stationary calculations were carried out. For this purpose, numerical and analytical algorithms have to be developed and applied to the spread, sedimentation, deposition and homogeneity of the AUSTAL authors in each individual case. Mathematics and mechanics alone are the methods used for clarification.

Literature studies are required to get to know the mathematics and mechanics of the AUSTAL dispersion model.

The work of von Axenfeld et al. (1984) must be studied. In cooperation with the first author of AUSTAL, Janicke, a model for calculating the dust precipitation is developed. The so-called Janicke Convention, which can be explained later in Sect. "Contradictory solution using the Janicke Convention according to Janicke (2002) and the difference to Berljand's boundary condition" is already there in the developed algorithms used. The thought model used describes deposition as loss and not as preservation.

With the scientific manual according to the VDI Commission for Air Pollution Control (1988) one wants to refer to the work Axenfeld et al. (1984) establish a new propagation theory.

The reference solutions and graphics belonging to the tasks for dispersion, sedimentation, deposition and homogeneity are explained in Janicke (2000).
With the intention of developing a national dispersion model, the model developed in 1984 for the calculation of dust precipitation in Janicke (2001) is further developed to the "mother model" LASAT.

The work Janicke (2002) describes tasks and tables for the calculation of dispersion, sedimentation, deposition and homogeneity.

The "Development of a model-based assessment system for immission control for companies" is described in Janicke et al. (2002) with the name AUSTAL2000 presented to the public. The BMU publication (2002) declares this model binding for all expert dispersion calculations. All other dispersion models have to prove their equivalence.

The work Trukenmüller et al. (2015) must be studied to get to know the derivation of the reference solutions declared binding for the first time. There the author of this article recognizes that all algorithms for this are wrong.

The reader has to laboriously collect the physical and mathematical foundations of model equations, tasks, solution algorithms, graphics and tables from seven publications individually. Other publications deal with applications and further developments at AUSTAL.

The publications Janicke (2009) and Janicke (2015) claim that the spread of radionuclides and aviation pollutants can be calculated. However, this would require non-stationary dispersion calculations, which AUSTAL is not able to do.

The author of this publication also studies Schorling (2009). With WinKFZ, the author develops an excellent model for calculating the spread of air pollutants, but it is discredited by court rulings because there is no equivalence to AUSTAL. The author subsequently wants to bring them about. However, it turns out that an approximate agreement can only be recognized visually. An actual equivalence cannot be inferred, since only unknown dimensionless pollutant concentrations are used. A clarification cannot be brought about. The author reckons with the superficiality of administrations rather than denying his excellent algorithms.

With the publications Trukenmüller (2016) one wants to achieve an equivalence to the correct reference solution according to Schenk (2018b). The author of this article looks at this publication and notes that it is simply a deception, as will be explained in more detail. The AUSTAL authors equate their wrong reference solution with the correct one. You get a simple algebraic equation and realize that there is no identity. You now rename variables and refer to the deposition rate $v_{d}[\mathrm{~m} / \mathrm{s}]$ of your wrong solution from now on $v_{d}^{\text {Janicke }}[\mathrm{m} / \mathrm{s}]$. The algebraic equation is now solved after the second deposition rate $v_{d}$ of the correct solution. At the end of the invoice, it will be 
renamed $v_{d}^{\text {Schenk }}[\mathrm{m} / \mathrm{s}]$. The accusation of an intention to deceive is well founded.

a. According to Trukenmüller et al. (2015) is known that both solutions are different. With the intention of manipulation, they are still equated. Left and right of the algebraic equation are the deposition velocities twice $v_{d}$.

b. The own deposition speeds $v_{d}$ are renamed with the intention to pretend equivalence in $v_{d}^{\text {Janicke }}$. After the second deposition rate $v_{d}$ the algebraic equation is solved.

c. At the end the second deposition speed $v_{d}$ is cleverly renamed to $v_{d}^{\text {Schenk. }}$

The accusation of deception is well founded. This castling can be studied in detail in Schenk (2017).

The fact that the difference between a numerical and analytical solution was still not understood in 2017 can be seen in Janicke et al. (2017) read. The heading shows that analytical methods are used for approximate solutions and numerical algorithms for exact solutions. The opposite is true.

The publication Trukenmüller (2017) describes a summary of the exchange of views held with the UBA regarding the validity of all reference solutions. Because the AUSTAL dispersion model is used in all areas of the economy, such as city and community planning, traffic planning, landscape design and also to avert danger, there is a high level of public interest in correctly carried out immission forecasts. For this reason, the public also has a right to be involved in discussions about the validity of this model development. There are no objections to publications on this. In the publication mentioned, those responsible for dispersion calculations according to TA Luft develop their thoughts on how they are responsible for promoting and accompanying model developments. In scientific discussions, however, they obviously rely more on the reputation of other well-known and valued authors than on their own competence. So you want to distract from your own ignorance. This wording is not very friendly. However, it is correct in every respect and affects not only the content but also the form of this publication. As far as the content is concerned, in connection with the definition of the deposition speed, one refers sequentially to authors such as Pasquill, Chamberlein, Berljand, Wiedensohler, Zhang, Slinn, Kumar, Cunningham, Monin, Kasanski, Bonka, Sehmen, Hodgson, Seinfeld, Pandis, Nicholson, Simpson and Travnikov. If one adds the work Trukenmüller (2016), the list is to be completed by the authors Venkatram and Pleim. Without a doubt, these authors have earned varying degrees of merit in the modeling of spreading, deposition and sedimentation and can point to an excellent reputation. However, they would definitely object if their research results on Trukenmüller (2017) were assumed to be equivalent. In the case of the first and the last of the authors cited, the ignorance of the AUSTAL authors can easily be demonstrated. Pasquill (1962), for example, is an excellent description of atmospheric diffusion, but in the relevant section "6.2 Deposition of airborne material" on 14 pages and 19 formulas, not a single statement can be found which indicates the violation of the Mass conservation and the Janicke's Convention could justify. The ignorance of the AUSTAL authors is that they are unable to use the excellent physics described there to develop a suitable thought model that would be accessible to a contradictory mathematical description. In the last of the cases cited, the author of this work deals intensively with the publication Venkatram et al. (1999) in Schenk R (2018b). The ignorance of the AUSTAL authors is that they did not understand that the one in Venkatram et al. (1999) found connection between sedimentation and deposition is only applicable for the special case of a disappearing soil concentration, $c_{0}\left[\mu \mathrm{g} / \mathrm{m}^{3}\right]=0$, which consequently with $F_{c}=v_{d} \cdot c_{0} \equiv 0$ not only questions all dispersion calculations, but also all other explanations by the authors of the AUSTAL on the validity of the Janicke Convention. According to the authors of AUSTAL, $F_{c}\left[\mu g /\left(m^{2} \cdot s\right)\right]$ means the total emission in the study area. It is also unlikely that the authors cited in the list believe that "... a column standing on the surface of the earth, which contains the material capable of deposition, runs empty through deposition", as in Axenfeld et al. (1984) is claimed. Also in the work Simpson et al. (2012) and Travnikov et al. (2005) there is no indication with which one could conclude that the Janicke Convention is valid. The accusation of ignorance is well founded. With regard to form, the style and expression of Trukenmüller (2017) snub every German authority.

In UBA (2018) the authors of AUSTAL complacently describe their history of the AUSTAL expansion model.

The publications, research projects, papers and studies mentioned here form the material that was to be analyzed using the methods described.

Basic knowledge can be found in the literature references Albring (1961), Берлянд (1975), Boŝnjakoviĉ (1971), Graedel et al. (1994), Gröber et al. (1955), Janenko (1968), Kneschke (1968), Naue (1967), Stephan et al. (1992), Schlichting (1964) and for, Schüle (1930), Truckenbrodt (1983) example also in Westphal (1959). These references are given to show that traditional mathematics and mechanics can be used as much as possible. Important physical basics and mathematical algorithms from AUSTAL are part of school knowledge.

External literature was also studied. For example, in Abas et al. (2019) brilliantly described that environmental 
protection is an international task. The calculation of cross-border pollutant flows allows a scientifically based cause analysis and promotes international cooperation. Cross-border pollutant flows can only be calculated using high-quality, scientifically based and validated dispersion models. The work by Schenk et al. (1979) and Schenk (1989) are of interest.

In the work Rafique et al. (2019) shows convincingly that population growth, energy policy and environmental protection are to be seen in a close connection. Political decisions cannot ignore this link. The development of the AUSTAL expansion model was also accompanied by political decisions.

If air quality monitoring is required, active measurement methods are often used. Using a pump, ambient air is drawn into the mini-volume collector (Mini-VS) and the dust contained in it is separated.

\section{Results}

Berljand's boundary condition, initial boundary value problem and integral theorems

\section{Boundary condition}

The spread of air pollutants is described by the initial boundary value task of the impulse, heat and mass transport. This includes the differential equation of mass transport (1).

$$
\frac{\partial \mathrm{c}}{\partial \mathrm{t}}+\mathrm{v}_{\mathrm{i}} \cdot \frac{\partial \mathrm{c}}{\partial \mathrm{x}_{\mathrm{i}}}=\frac{\partial}{\partial \mathrm{x}_{\mathrm{i}}}\left(K \cdot \frac{\partial \mathrm{c}}{\partial \mathrm{x}_{\mathrm{i}}}\right)+\dot{q}(\mathrm{t})
$$

which can be solved with suitable starting and boundary conditions. In this equation, $c\left[\mu \mathrm{g} / \mathrm{m}^{3}\right]$ explain the concentration, $x_{i}[m]$ the coordinates in the different spatial directions, $K\left[\mathrm{~m}^{2} / \mathrm{s}\right]$ the diffusion coefficient in the free atmosphere, $\dot{q}(t)\left[\mu g /\left(m^{3} \cdot s\right)\right]$ the source term, $v_{i}[m / s]$ the flow velocity and $t[s]$ the time coordinate.

In the case of a one-dimensional and non-stationary propagation, the differential Eq. (2).

$$
\frac{\partial c}{\partial t}-v_{s} \cdot \frac{\partial c}{\partial z}=K \cdot \frac{\partial^{2} c}{\partial z^{2}}+\dot{q}(t)
$$

is obtained according to Eq. (1), and in the stationary case if the source term $\dot{q}(t)=0$ is missing, the relationship (3).

$$
-v_{s} \cdot \frac{\partial c}{\partial z}=K \cdot \frac{\partial^{2} c}{\partial z^{2}} .
$$

In these equations, besides the already known quantities $v_{s}[\mathrm{~m} / \mathrm{s}]$ means the sedimentation speed and $z[\mathrm{~m}]$ the vertical position coordinate. With a view to later applications, it is negative. For further considerations, various simplifications are of interest for Eq. (1).

$$
\frac{d c}{d t}=\dot{q}(t)
$$

Equation 4 describes the simple further development of an equally distributed initial concentration $c_{A}\left[\mu \mathrm{g} / \mathrm{m}^{3}\right]$, neglecting all convective and conductive material flows. This equation can be obtained, for example, if spatial concentration changes are not observed, $\partial / \partial x_{i}=0$.

In the case of a time-independent source term $\dot{q}(t)=\dot{q}=$ const., the relationships of (5).

$$
\mathrm{c}(\mathrm{t})=\mathrm{c}_{\mathrm{A}}+\int_{0}^{T} \dot{q} \cdot d t \quad \mathrm{c}(\mathrm{t})=\mathrm{c}_{\mathrm{A}}+\dot{q} \cdot t
$$

explain a linear increase in concentration as a solution of (4), where $T_{E}[s]$ denotes the end of emission.

The boundary condition belonging to Eq. (1) is derived from the mass constancy at the control limits between atmosphere and soil. It is known as the Berljand boundary condition. The relationships to this are described in Fig. 1. All representations have been selected so that they can be applied directly to the study areas of the AUSTAL authors to derive the reference solutions. The ordinate $x_{i}$ is directed into the free atmosphere and the coordinate $x_{i}^{*}[m]$ points from the depth of the earth towards the boundary. With $x_{i}(0)$ and $x_{i}^{*}[T]$ the soil and atmosphere touch. In order to establish a relationship with the reference solutions of the AUSTAL authors, the coordinate notation $x_{3}=z$ and $x_{3}^{*}=z^{*}$ is used for $i=3$ below. This is how $\dot{m}^{A}=\dot{m}_{z}^{A}=\int d \dot{m}_{z}^{A}=\dot{m}^{A}\left[\mu g /\left(m^{2} \cdot s\right)\right]$ designates the conductive material flow in the free atmosphere and $\dot{m}^{B}=\dot{m}_{z}^{B}=\int d \dot{m}_{z}^{B}=\dot{m}^{B}\left[\mu g /\left(m^{2} \cdot s\right)\right]$ in the depth of the earth. There is a surface source in the

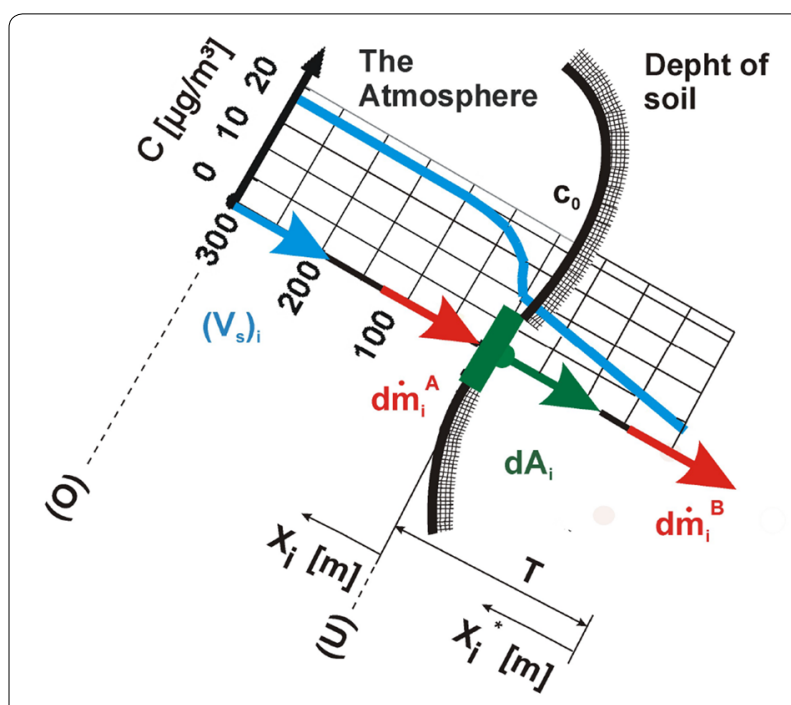

Fig. 1 General validity of Berljand's boundary Condition 
atmosphere. The pollutants emitted there move convectively and conductively towards the ground. The sedimentation flow $\dot{m}^{S}\left[\mu g /\left(m^{2} \cdot s\right)\right]$ is calculated as the product of concentration and sedimentation rate, $\dot{m}^{S}(z)=-c \cdot v_{s}$. The conductive material flows are represented as products between the diffusion coefficients and the concentration gradients, $\dot{m}^{A}(z)=-K \cdot \partial c / \partial z$ and $\dot{m}^{B}\left(z^{*}\right)=-K_{B} \cdot \partial c / \partial z^{*}$. The $K_{B}\left[m^{2} / s\right]$ is the diffusion coefficient in the soil. At the lower boundary of the study area, the identical conductive material flows are obtained for $z^{*}=T$ and $z=0$.

$$
\dot{m}^{A}(z=0)=\dot{m}^{B}\left(z^{*}=T\right)
$$

$T[m]$ means the depth in the ground.

The sedimentation rate in the soil itself is identical to zero. With $v_{s}=0$ according to Eq. (3) one obtains the simple relationship $\partial^{2} c / \partial z^{* 2}=0$. The boundary conditions $c\left(z^{*}=T\right)=c_{0}$ and $c\left(z^{*}=0\right)=c_{T}$ result in a linear concentration distribution in the soil, which is described by Eq. (7).

$$
c=\frac{c_{0}-c_{T}}{T} \cdot z^{*}+c_{T} .
$$

Under $c_{T}\left[\mu \mathrm{g} / \mathrm{m}^{3}\right]$ is to be understood the concentration in great depth of the soil and under $c_{0}\left[\mu \mathrm{g} / \mathrm{m}^{3}\right]$ the soil concentration. Because of the constant mass, the conductive material flows on the floor must be identical. This gives

$$
\begin{aligned}
K \cdot \frac{\partial c}{\partial z}(0) & =K_{B} \cdot \frac{\partial c}{\partial z^{*}}(T)=\frac{K_{B}}{T} \cdot\left(c_{0}-c_{T}\right) \\
& \approx \frac{K_{B}}{T} \cdot c_{0}=v_{d} \cdot c_{0}
\end{aligned}
$$

and

$$
v_{d}=\frac{K_{B}}{T}
$$

Equation (8) also gives the definition of the deposition rate, as can be seen from Eq. (9). Equation (8) assumes that the soil can absorb material capable of deposition without restriction, which is why one can set $c_{T} \approx 0$. Equation (8) finally gives Berljand's boundary conditions (10).

$$
K \cdot \frac{\partial c}{\partial z}(0)-v_{d} \cdot c_{0}=0 .
$$

It is identical to Eq. (11)

$$
K \cdot \frac{\partial c}{\partial x_{i}}(0)-\beta_{i} \cdot c_{0}=0,
$$

as can be found in Берлянд (1975). The mass transfer rate is to be understood under $\beta_{i}[\mathrm{~m} / \mathrm{s}]$. In the case of deposition, the deposition speed means $v_{d}=\beta_{3}$, which means $i=3$ is the direction in which the pollutants are deposited.

The Berljand boundary condition is well known and is used in particular to describe the spread, deposition and sedimentation. This preferably affects the research area of the spread of air pollutants, but it is also not unknown in other disciplines, such as fluid mechanics, thermodynamics and process engineering, for the calculation of convective and conductive material flows.

\section{Initial boundary value task}

The boundary value task for one-dimensional spreading, sedimentation and deposition is described by the balance Eq. (2) and by the boundary condition (10). In the case of an initial boundary value task, the initial condition (12)

$$
c\left(x_{1}, x_{2}, x_{3}, t=0\right)=c_{A}\left(x_{1}, x_{2}, x_{3}\right)
$$

to be added. $x_{1,2,3}[m]$ mean the three-dimensional spatial coordinates.

The closed initial boundary value task is therefore explained by the formula (13)

$$
\frac{\partial c}{\partial t}-v_{s} \cdot \frac{\partial c}{\partial z}=K \cdot \frac{\partial^{2} c}{\partial z^{2}}+\dot{q}(t)
$$

Model equation

$$
K \cdot \frac{\partial c}{\partial z}(0)-v_{d} \cdot c_{0}=0
$$

Boundary condition

$c\left(x_{1}, x_{2}, x_{3}, t=0\right)=c_{A}\left(x_{1}, x_{2}, x_{3}\right)$

Initial condition

\section{Volume and area integrals}

To prove mass conservation, one starts from the differential Eq. (1) and forms volume integrals according to Eq. (14)

$$
\begin{aligned}
& \int_{V} \frac{\partial c}{\partial t} \cdot d V+\int_{V} v_{i} \cdot \frac{\partial c}{\partial x_{i}} \cdot d V \\
& \quad=K \cdot \int_{V} \frac{\partial^{2} c}{\partial x_{i} \partial x_{i}} \cdot d V+\int_{V} \dot{q}(t) \cdot d V .
\end{aligned}
$$

Using the Gaussian theorem, volume integrals can be converted into surface integrals. This leads to the relationship (15) with two orbital integrals.

$$
\int_{V} \frac{\partial c}{\partial t} \cdot d V+\oint_{A} v_{i} \cdot c \cdot d A_{i}=K \cdot \oint_{A} \frac{\partial c}{\partial x_{i}} \cdot d A_{i}+\int_{V} \dot{q}(t) \cdot d V .
$$

In this equation, $A\left[\mathrm{~m}^{2}\right]$ means the surface and $V\left[\mathrm{~m}^{3}\right]$ the volume of the control area. Integration over the surface of the study area leads to Eq. (16). 


$$
\begin{aligned}
& \int_{V} \frac{\partial c}{\partial t} \cdot d V+v_{i}(0) \cdot c(0) \cdot \int_{U} d A_{i}+v_{i}(h) \cdot c(h) \cdot \int_{O} d A_{i} \cdot \\
& =K \cdot \frac{\partial c}{\partial x_{i}}(0) \cdot \int_{U} d A_{i}+K \cdot \frac{\partial c}{\partial x_{i}}(\mathrm{~h}) \int_{O} d A_{i}+\int_{V} \dot{q}(t) \cdot d V
\end{aligned}
$$

The integration can be carried out because the integrants are constant over the respective boundary surfaces below $(\mathrm{U})$ and above $(\mathrm{O})$. An integration over side surfaces can be dispensed with, since due to the lack of flow velocities and concentration levels, no mass transfer can take place. If you consider that all surface vectors are directed positively outwards, the scalar products can also be formed. This results in Eqs. (17).

$$
\begin{aligned}
\int_{V} & \frac{\partial c}{\partial t} \cdot d V+v_{s} \cdot c_{0} \cdot A_{U}-v_{s} \cdot c_{h} \cdot A_{O} \\
& =-K \cdot \frac{\partial c}{\partial z}(0) \cdot A_{U}+K \cdot \frac{\partial c}{\partial z}(\mathrm{~h}) \cdot A_{O}+\int_{V} \dot{q}(t) \cdot d V .
\end{aligned}
$$

Here, $A=A_{O}=A_{U}\left[m^{2}\right]$ mean the control areas at the top and bottom edges and $c_{h}\left[\mu g / m^{3}\right]=c(z=h)$ the concentration at the top. $h[m]$ is to be understood as the vertical extent of the study area. Also note that Eq. (18) is obtained.

$$
\begin{gathered}
\int_{0}^{h} \frac{\partial c}{\partial t} \cdot d z+v_{s} \cdot c_{0}-v_{s} \cdot c_{h}+v_{d} \cdot c_{0} \\
-K \cdot \frac{\partial c}{\partial z}(\mathrm{~h})-\int_{0}^{h} \dot{q} \cdot d z=0 .
\end{gathered}
$$

This equation can be used to check the validity of all reference solutions with regard to mass conservation.

For later considerations, Eq. (19)

$$
Q=1 / A \cdot \int_{V} \dot{q} \cdot d V \cdot=\int_{0}^{h} \dot{q} \cdot d z
$$

of interest. The source term is to be understood as $Q\left[\mu g /\left(m^{2} \cdot s\right)\right]$. (20)

In the case of steady-state expansion, the mass balance

$$
v_{s} \cdot c_{0}-v_{s} \cdot c_{h}+v_{d} \cdot c_{0}-K \cdot \frac{\partial c}{\partial z}(\mathrm{~h})=0 .
$$

is obtained from a comparison between Eqs. (2) and (3) because of $\partial \mathrm{c} / \partial \mathrm{t}=0$.
Calculation of concentration, sedimentation and deposition for a one- dimensional spread of air pollutants

Conflict-free solution using the Berljand boundary condition according to Schenk (2018b)

The correct solution of the differential Eq. (3) can be found in Schenk (2018b). It is described by Eqs. (21)

$$
c(z)=c_{0} \cdot \frac{v_{s}+v_{d}}{v_{s}} \cdot\left[1-\frac{v_{d}}{v_{s}+v_{d}} \cdot \exp \left(-\frac{v_{s}}{K} \cdot z\right)\right]
$$

and (22). Equation (21) explains the course of the solution as a function of the deposition and sedimentation velocities $v_{d}$ and $v_{s}$, the height coordinate $z$, the diffusion coefficient $K$ and the soil concentration $c_{0}$, which can be determined using Eq. (22).

$$
c_{0}=\frac{Q}{\left(v_{s}+v_{d}\right)} .
$$

With known model parameters, concentration distributions, deposition and sedimentation flows as well as soil concentrations can be calculated.

For later use, Eq. (21) also gives the first derivative.

$$
\frac{\partial c}{\partial z}=c_{0} \cdot \frac{v_{d}}{K} \cdot \exp \left(-\frac{v_{s}}{K} \cdot z\right) .
$$

and for $z=0$.

$$
\frac{\partial c}{\partial z}(0)=c_{0} \cdot \frac{v_{d}}{K} .
$$

Equation (24) proves that solution (21) fulfills Berljand's boundary condition (10). With this boundary condition one understands deposition storage and not loss.

Contradictory solution using Janicke's Convention according to Janicke (2002) and the difference to the Berljand boundary condition

The incorrect solution is described in Trukenmüller et al. (2015) given by the relationships (25) and (26).

$$
c(z)=c_{0} \cdot \exp \left(-z \cdot \frac{v_{s}}{K}\right)+\frac{F_{c}}{v_{s}} \cdot\left[1-\exp \left(-z \cdot \frac{v_{s}}{K}\right)\right],
$$

and

$$
F_{c}=c_{0} \cdot v_{d}
$$

The authors of AUSTAL use Eq. (25) to calculate the wrong concentration distribution, and Eq. (26) begins the confusion. First, $F_{c}\left[\mu g /\left(m^{2} \cdot s\right]\right.$ according to Eq. (26) has the meaning of a deposition and later again according to Eq. (30) that of a sedimentation stream. The authors of AUSTAL do not realize that both interpretations are 
wrong. In the end, you make a decision and mean according to VDI 3945 Sheet 3 (2000) and Janicke (2002) "the mass flow density deposited on the ground" according to Eq. (6) and Eq. (27).

$$
\dot{m}^{B}=F_{c} \text {. }
$$

Equation (26) is used to calculate the soil concentration.

$$
c_{0}=\frac{F_{c}}{v_{d}},
$$

and does not care what happens if there is no deposition stream with $v_{d} \equiv 0$.

It is of interest to learn how to understand the Janicke Convention. In the course of the derivation of Eq. (25), the authors of AUSTAL receive the relationship (29).

$$
F_{c}=K \cdot \frac{\partial c}{\partial z}+v_{s} \cdot c .
$$

It results from the one-time integration of the differential Eq. (3), where $F_{c}$ has the meaning of an integration constant, which would have been determined using Berljand's boundary condition. Instead, the authors of AUSTAL use a constant concentration distribution as a special solution for $F_{c}$ according to Eq. (30).

$$
F_{c}=v_{s} \cdot c_{i}=\text { const }
$$

With the specification of this special solution $c_{i}\left[\mu \mathrm{g} / \mathrm{m}^{3}\right]$ it can subsequently be seen from Eq. (31).

$$
c_{i}=c(z)=c(0)=c_{0}=\text { const. }
$$

that the concentration value of $c_{i}$ also means the soil concentration $c_{0}$. This gives the relationship (32).

$$
F_{c}=v_{s} \cdot c_{0} .
$$

Equations (25) and (30) can be used to prove the worthlessness of the solution function (25) according to Eq. (33).

$$
\begin{array}{r}
c(z)=c_{0} \cdot \exp \left(-z \cdot \frac{v_{s}}{K}\right)+\frac{c_{i} \cdot v_{s}}{v_{s}} \cdot\left[1-\exp \left(-z \cdot \frac{v_{s}}{K}\right)\right]= \\
c_{0} \cdot \exp \left(-z \cdot \frac{v_{s}}{K}\right)+\frac{c_{0} \cdot v_{s}}{v_{s}} \cdot\left[1-\exp \left(-z \cdot \frac{v_{s}}{K}\right)\right]=c_{0}
\end{array}
$$

already mentioned. This integral of the differential Eq. (3) cannot be used to perform simulations for determining concentration distributions. The AUSTAL authors recognize the uselessness of the special solution used (31). Instead of changing the solution method, for example, according to Kneschke (1968), they swap the sedimentation stream $v_{s} \cdot c_{0}$ with the deposition stream $v_{d} \cdot c_{0}$ without reason and refer to their self-written convention in VDI 3945 Part 3 (2000) and claim that it would be universal. Instead of Eq. (30), Eq. (26) $F_{c}=v_{d} \cdot c_{0}$ is used for no reason. After criticism, Trukenmüller (2017) assures that this castling would also be used by the authors Simpson et al. (2012) and Venkatram et al. (1999) used. "Worldwide, the dispersion models are based on the definition of the deposition speed that is recognized in the literature", the AUSTAL authors in Trukenmüller (2017) affirm, but this is not confirmed.

One should know that sedimentation and deposition flows, $v_{s} \cdot c_{0}$ and $v_{d} \cdot c_{0}$, can be explained physically differently. They cannot be exchanged at will. Incidentally, the castling of $v_{s} \cdot c_{0}$ by $v_{d} \cdot c_{0}$ differentially violates the mass conservation rate, as was demonstrated in Schenk (2018b). With this poorly thought-out knowledge, the authors of AUSTAL finally obtained the wrong Janicke Convention (34) from Eqs. (23) and (29) for $z=0$, which is used as a boundary condition.

$$
F_{c}=K \cdot \frac{\partial c}{\partial z}+v_{s} \cdot c=v_{d} \cdot c_{0} .
$$

Trukenmüller (2017) later asserts that Eq. (34) is the "true" definition of the deposition rate. It would represent deposition flows parameterized. If you add the two other definitions given initially in Trukenmüller (2016), it is now the third definition. One does not want to learn that the deposition speed $v_{d}=K_{B} / T$ according to Eq. (9) can be regarded as a material constant.

Here, too, the first derivatives of Eq. (25) are of interest,

$$
\frac{\partial c}{\partial z}=\frac{1}{K} \cdot \exp \left(-\frac{v_{s}}{K} \cdot z\right) \cdot\left(F_{c}-c_{0} \cdot v_{s}\right)
$$

and for $z=0$.

$$
\frac{\partial c}{\partial z}(0)=\frac{1}{K} \cdot\left(F_{c}-c_{0} \cdot v_{s}\right)
$$

for subsequent use.

Equation (36) proves that the solution (25) by the AUSTAL authors does not meet Berljand's boundary condition (10). Taking Eq. (26) $F_{c}=c_{0} \cdot v_{d}$ into account, Eq. (36) is identical to the Janicke Convention.

The difference between Janicke's Convention on Berljand's boundary condition can be seen in the comparison of Eqs. (10) and (34). It is described with the formula (37). It can be seen that this convention results in a mass deficit of $-c_{0} \cdot v_{s}$ at the area boundary from atmosphere to ground.

$K \cdot \frac{\partial c}{\partial z}(0)-v_{d} \cdot c_{0}=0$

Berljand's boundary condition

$K \cdot \frac{\partial c}{\partial z}(0)-v_{d} \cdot c_{0}=-c_{0} \cdot v_{s}$ 


\section{Reference solutions for dispersion, deposition, sedimentation and homogeneity Assessment of the tasks}

The authors of AUSTAL have failed to explain their tasks, model parameters and algorithms for deriving the reference solutions uniformly in a publication. The reader must collect all information about the task, the solution algorithms as well as numerical and graphical evaluation from various publications. With this confusion and trust in the authority of the administration, one can justify why in the past only a few critics have found themselves concerned with the theoretical foundations of AUSTAL. It is only after 31 years that Trukenmüller et al. (2015) read about the derivation of the reference solutions for the first time.

In this section, examples of "sedimentation without deposition", "Deposition with sedimentation", and "homogeneity" are used to check all information provided by the AUSTAL authors for credibility and to show contradictions. The tasks explained by the authors of AUSTAL are only slightly different. A uniform three-dimensional control volume is considered, although it is only a matter of zero-dimensional and one-dimensional propagation processes. Time-dependent simulation results are given uniformly. In all cases, it is said that time series over 10 days were expected. The emission occurs only in the first hour of the first day, and the stationary solutions would have appeared after 10 days in all cases. Algorithms and graphics for non-stationary calculations are not described. The AUSTAL authors provide incorrect stationary solutions for all reference cases. Non-stationary calculations are not carried out at all, although simulation results are also given for this. In order to be able to provide credible evidence for this, stationary and non-stationary calculations are carried out for all case studies.

The first and second options distinguish between nonstationary and stationary bills. The correct solutions are compared to the wrong ones.

\section{Sedimentation without deposition}

Task The task for the "sedimentation without deposition" propagation process according to Fig. 2 is taken from the literature reference Janicke (2002).

The model parameters and simulation results can be summarized.

a) "The emission occurs only in the first hour of the first day", which means $T_{E}=3600$.

b) The simulation is completed on the "10th day" with $t=240 \mathrm{~h}$.

c) One calculates a "time series over 10 days". d) The size of the control volume is specified with the geometric lengths $L_{x}[m]=1000, L_{y}[m]=1000$ and $L_{z}[m]=200$.

e) There is no "mass flow density forced by the source", $F_{c}=0$,

f) "Volume source distributed over the entire computing area".

g) In the literature reference Janicke (2000) one learns for this case of spread that the mean concentration is $\bar{c}\left[\mu g / m^{3}\right]=500$.

h) The sedimentation rate and the diffusion coefficient are $v_{s}=0,01$ and $K=1$.

i) Because "A mass flow density enforced by the source" does not exist, $F_{c}=0$, the deposition velocity $v_{d}=0$ disappears, since only $c_{0} \neq 0$ can be valid for the soil concentration.

From the task described it appears authentically that one means a non-stationary propagation process, for which only the differential Eq. (2) is responsible. Regardless of this, the authors of AUSTAL assume in their solution process according to Eq. (3) a stationary propagation process. A solution (25) is also given for this. It is not known who should understand this.

Correct non-stationary and stationary solution taking into account the Berljand boundary according to Schenk (2018b)

\section{First option, non-stationary consideration}

In the case of a non-stationary consideration, the differential Eq. (2) with the initial condition (12) with $c_{A}=0$ applies. The total emission $m_{E}[\mathrm{~kg}]$ can be determined from the specified mean concentration $\bar{c}$. The geometric information d) for the size of the study area then gives the numerical expression (38).

$$
\begin{aligned}
m_{E} & =\bar{c} \cdot V=\bar{c} \cdot L_{x} \cdot L_{y} \cdot L_{z} \\
& =500 \cdot 1000 \cdot 1000 \cdot 200 \cdot \frac{1}{10^{9}}=100
\end{aligned}
$$

With the specification a) the emission is ended according to $1 \mathrm{~h}$. This enables the source term $\dot{q}=$ const. $0<\mathrm{t} \leq \mathrm{T}_{\mathrm{E}}$ of the differential Eq. (2) to be determined. Together with $V=L_{x} \cdot L_{y} \cdot L_{z}=2 \cdot 10^{8}$, the numerical value can be given using Eq. (39).

$$
\begin{aligned}
& \dot{q}=\frac{m_{E}}{V \cdot T_{E}}=\frac{100}{2 \cdot 10^{8} \cdot 3600} \cdot 10^{9}=0,139 \quad 0 \leq t \leq T_{E} \\
& \dot{q}=0 \quad \mathrm{t}>\mathrm{T}_{\mathrm{E}} .
\end{aligned}
$$

In addition, the specification $\mathrm{f}$ ) must be taken into account that the "volume source is distributed over the 


\section{2a Depositionstest: Sedimentation ohne Deposition}

Hat man sedimentierende Partikel, die nicht deponiert werden, dann stellt sich, ähnlich wie bei der barometrischen Höhenformel, eine exponentielle Dichteverteilung ein, die man aus Gleichung (26) durch die Spezialisierung auf $\mathrm{F}_{\mathrm{c}}=0$ erhält.

\begin{tabular}{rrrrr} 
I & \multicolumn{1}{c}{ II } & \multicolumn{1}{c}{ III } & \multicolumn{1}{c}{ IV } & \multicolumn{1}{c}{ V } \\
K & Cmin & C & Cmax & \multicolumn{1}{c}{ Csol1 } \\
1 & 1082.3 & 1111.2 & 1140.1 & 1100.6 \\
2 & 978.2 & 1000.2 & 1022.2 & 995.8 \\
3 & 889.4 & 907.5 & 925.6 & 901.1 \\
4 & 801.8 & 816.5 & 831.2 & 815.3 \\
5 & 723.2 & 738.0 & 752.8 & 737.7 \\
6 & 656.2 & 669.6 & 683.0 & 667.5 \\
7 & 582.4 & 594.3 & 606.2 & 604.0 \\
8 & 523.7 & 535.5 & 547.3 & 546.5 \\
9 & 475.7 & 487.4 & 499.1 & 494.5 \\
10 & 432.1 & 443.6 & 455.1 & 447.5 \\
11 & 392.5 & 404.6 & 416.7 & 404.9 \\
12 & 353.8 & 365.5 & 377.2 & 366.3 \\
13 & 315.3 & 327.1 & 338.9 & 331.5 \\
14 & 282.9 & 294.1 & 305.3 & 299.9 \\
15 & 259.4 & 270.2 & 281.0 & 271.4 \\
16 & 236.1 & 247.0 & 257.9 & 245.6 \\
17 & 217.5 & 228.5 & 239.5 & 222.2 \\
18 & 199.6 & 210.5 & 221.4 & 201.1 \\
19 & 173.7 & 184.4 & 195.1 & 181.9 \\
20 & 154.5 & 165.4 & 176.3 & 164.6
\end{tabular}

Rechengebiet: $1000 \times 1000 \times 200 \mathrm{~m}^{3}$, aufgeteilt in $1 \times 1 \times 20$ Maschen (vertikal äqudistant) mit periodischen Randbedingungen.

Meteorologie: Homogene Turbulenz mit ua $=0,2$, $z 0=0,08$ und $" B \mathrm{~lm}=0,1 ; S w=0,5 \quad \mathrm{Tau}=2, \mathrm{vs}=0,01$; Us=0,2;" Zeitreihe über 10 Tage.

Quelle: Volumenquelle über das gesamte Rechengebiet. Die Emission erfolgt nur in der ersten Stunde des ersten Tages. Bei Groups $=36$; Rate 0.1 ; bedeutet dies, daß das jede Gruppe 10 Partikel enthält.

Die nebenstehende Tabelle enthält für den 10ten Tag das Vertikalprofil (Index K) der Konzentration (Spalte C). Aus dem vom Programm ausgewiesenen Stichprobenfehler, der hier zwischen $1 \%$ und $3 \%$ liegt sind die untere Grenze (Spalte Cmin)

und obere Grenze (Spalte Cmax) des 95-Prozent-Vertrauensintervalls gebildet. Die Spalte Csoll enthält die theoretischen Werte entsprechend Gleichung (26) mit $F_{c}=0 \mu g /\left(m^{2} \cdot s\right)$, $v_{s}=0,01 \mathrm{~m} / \mathrm{s}, K=1 \mathrm{~m}^{2} / \mathrm{s}$. Alle Werte liegen innerhalb des Vertrauensintervall.

Fig. 2 Task of the AUSTAL authors "Sedimentation without Deposition"

entire computing area", which means that there are no spatial concentration gradients, $\partial c / x_{i}=\partial c / z=0$. This simplifies Eq. (2) to Eq. (4). A simple integration with the initial condition $c_{A}=0$ gives the calculated value and Eq. (40).

$$
\begin{aligned}
& \mathrm{c}(\mathrm{t})=\mathrm{c}_{\mathrm{A}}+\dot{q} \cdot t \\
& \mathrm{c}\left(\mathrm{T}_{\mathrm{E}}\right)=\mathrm{c}_{\mathrm{A}}+\dot{q} \cdot T_{E}=0+0,139 \cdot 3600 \approx 500 .
\end{aligned}
$$

For $t>T_{E}$ and because of Eq. (39) as well as Eq. (4), $\dot{q}=0$ and $d c / d t=0$, this solution cannot be developed further. The concentration of $c=500$ reached remains constant over time. Equation (40) describes zero-dimensional propagation with the time coordinate as the only independent variable.
The results are shown in graphs A and B in Fig. 3. The graphic A describes the time-dependent course of the filling in the interval $0 \leq t \leq T_{E}$ and for $t>T_{E}$. Graph $B$ further explains that there is no vertical concentration gradient, $\partial c / z=0$. The concentrations remain spatially and temporally unchangeable for all simulation times. The results prove that the statement $b$ ) by the AUSTAL authors that the steady state would only be reached after 10 days is not correct. The concentration value of $c=500$ has already set after $1 \mathrm{~h}, T_{E}=3600$. According to c) it is said that a time series of 10 days was expected, which cannot be confirmed either. The trivial solution (40) is comparable to filling different containers with different media. 
It would have to be proven that the solution fulfills the mass conservation law after the first option. The integral Eq. (18) is used for this. According to h), the sedimentation rate in the entire control room is $v_{s}=0,01$. The concentrations are spatially constant at all simulation times, so that the identity $c_{0}(t) \equiv c_{h}(t)$ can be assumed. In addition, the integrals of Eq. (18) can be calculated with $\partial c / \partial t=\dot{q}$.

According to task i) no deposition should take place, $v_{d}=0$. Because of the spatially constant concentration, $\partial c / d z(h)=0$ is also valid. The integral Eq. (41).
Second option, stationary viewing

The second option alternatively considers a stationary propagation process. The corresponding correct stationary solution is described by Eqs. (21) and (22). After e) the task, there are no mass flow densities, which means $F_{c}=Q=0$. According to this, no pollutant can be found in the study area, which is also confirmed by the trivial solutions (43).

$$
c_{0}=\frac{Q}{\left(v_{s}+v_{d}\right)}=\frac{0}{(0,01+0)}=0
$$

$$
\begin{array}{llllll}
\int_{0}^{h} \frac{\partial c}{\partial t} \cdot d z & +v_{s} \cdot c_{0} & -v_{s} \cdot c_{h} & +v_{d} \cdot c_{0} & -K \cdot \frac{\partial c}{\partial z}(\mathrm{~h}) & -\int_{0}^{h} \dot{q} \cdot d z=0 \\
\dot{q} \cdot h & +v_{s} \cdot c_{0}(t) & -v_{s} \cdot c_{h}(t) & +0 \cdot c_{0}(t) & -K \cdot 0 & -\dot{q} \cdot h
\end{array},
$$

gives that the mass conservation law is fulfilled for all simulation times if the solutions are correct. Because of $\partial c / \partial z(z, t) \equiv 0$ according to Eq. (40) and Eq. (6), $\dot{m}^{A}=\dot{m}^{B}$, no deposition takes place according to Eq. (42)

$$
\dot{m}^{B}(t)=-K \cdot \frac{\partial c}{\partial z}(0, t) \equiv 0
$$

The deposition stream $\dot{m}^{B}$ and the conductive material stream $-K \cdot \partial c / \partial z(0)$ are identical zero.They coincide according to amount and direction. The second law of thermodynamics is fulfilled. and (44).

$$
\begin{gathered}
c(z)=c_{0} \cdot \frac{v_{s}+v_{d}}{v_{s}} \cdot\left[1-\frac{v_{d}}{v_{s}+v_{d}} \cdot \exp \left(-\frac{v_{s}}{K} \cdot z\right)\right]= \\
0 \cdot \frac{0,01+0}{0,01} \cdot\left[1-\frac{0}{(0,01+0)}\left(\exp \left(-\frac{0,01}{1} \cdot z\right)\right)\right]=0
\end{gathered}
$$

The result is shown in Fig. 3, graphic C.

For the sake of completeness alone, it should be proven that the mass conservation law is fulfilled. Equation (20) can be assumed.

$$
\begin{aligned}
& v_{s} \cdot c_{0} \quad-v_{s} \cdot c_{h} \quad+v_{d} \cdot c_{0} \quad-K \cdot \frac{\partial c}{\partial z}(\mathrm{~h})=0 \\
& 0,01 \cdot 500-0,01 \cdot 500+0.500-1 \cdot 0 \equiv 0
\end{aligned}
$$

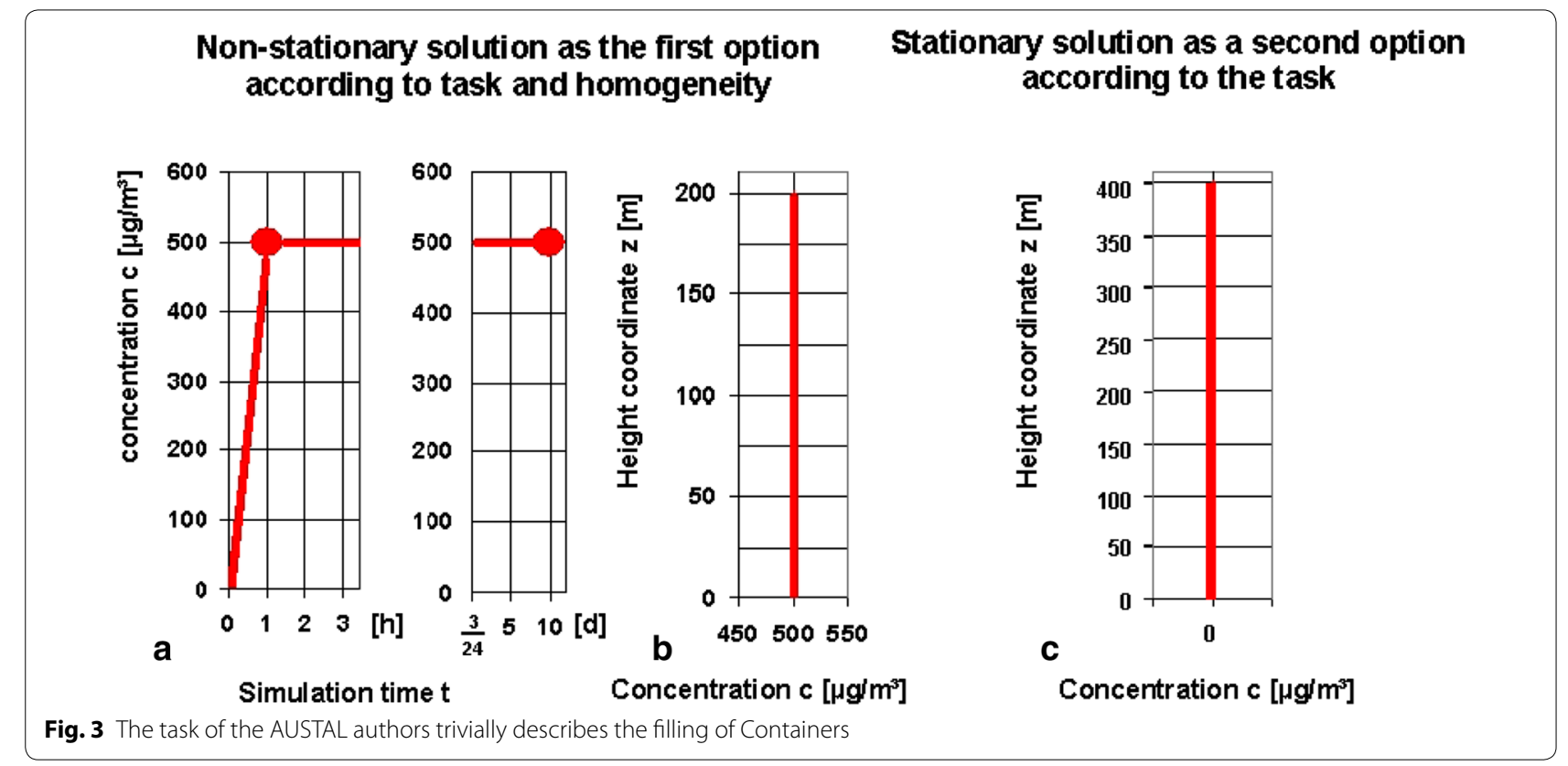


With the appropriate calculation parameters, mass conservation is guaranteed.

Because of $\partial c / \partial z(0)=0$ and Eq. (44) and considering Eq. (6) $\dot{m}^{A}=\dot{m}^{B}$, Eq. (46).

$$
\dot{m}^{B}=-K \cdot \frac{\partial c}{\partial z}(0)=-1 \cdot 0=0
$$

results. After that, there is no conductive mass transfer, $\dot{m}^{B}=0$. After i) the task, no deposition should take place $F_{c}=0$. Because of a missing potential gradient $\partial c / \partial z(0)=0$, this does not take place either, $\dot{m}^{B}=$ $-K \cdot \partial c / \partial z(0)$. The second law of thermodynamics is fulfilled.

Faulty non-stationary and stationary solution taking into account the Janicke Convention according to Trukenmüller et al. (2015)

\section{First option, non-stationary consideration}

First, a non-stationary view is assumed. After a) "The emission only occurs in the first $h$ of the first day", b) the stationary solution is reached on the "10th day" and c) a "time series over 10 days" is calculated, it is a non-stationary task. However, no solution algorithms and concentration profiles are described for this. For this reason, the integral Eqs. (18) and (20).

$$
\begin{gathered}
\int_{0}^{h} \frac{\partial c}{\partial t} \cdot d z+v_{s} \cdot c_{0}-v_{s} \cdot c_{h}+v_{d} \cdot c_{0} \\
-K \cdot \frac{\partial c}{\partial z}(\mathrm{~h})-\int_{0}^{h} \dot{q} \cdot d z=0
\end{gathered}
$$

cannot be used. The authors of AUSTAL remain guilty of the answer, which is why a stationary concentration distribution should have set in after 10 days.

\section{Second option, stationary viewing}

The second option describes a stationary view. The authors of AUSTAL assume the stationary differential Eq. (3) and state the solution functions (25) and (26). First, the soil concentration would have to be calculated again according to Eq. (26). However, due to i), $F_{c}=0$ and without deposition, $v_{d}=0$, an indefinite expression is obtained for calculating the soil concentration $c_{0}$, $c_{0}=0 / 0$. Equation (25) is simplified because of e) to the exponential function (48).

$$
c(z)=c_{0} \cdot \exp \left(-z \cdot \frac{v_{s}}{K}\right) .
$$

Because the soil concentration $c_{0}$ cannot be calculated according to Eq. (26), a volume source is introduced without further ado after $\mathrm{f}$ ). According tog), the pollutant particles with a concentration of $\bar{c}=500$ are in a thermodynamic equilibrium. Speculatively, these are now redistributed so that they follow the exponential function (48). The second law of thermodynamics is already violated, because mass transport only takes place against the concentration gradient and not vice versa. You don't necessarily have to have doctrine, such as according to Westphal (1959), page 265, cite that mass transport "... never by itself in the reverse sense" can be observed. The authors of AUSTAL reverse all basic knowledge to the contrary and calculate speculatively with Eq. (49) a soil concentration of $c_{0}=1100,6$

$$
\begin{aligned}
c_{0}= & c(z=5)=\bar{c} \cdot \frac{v_{s} \cdot L_{z}}{K} \\
& \cdot \frac{1}{\left[1-\exp \left(-\frac{v_{s} \cdot L_{z}}{K}\right)\right]} \cdot \exp \left(-\frac{v_{s}}{K} \cdot 5\right) \\
= & 500 \cdot \frac{0,01 \cdot 200}{1} \cdot \frac{1}{\left[1-\exp \left(-\frac{0,01 \cdot 200}{1}\right)\right]} . \\
& \cdot \exp \left(-\frac{0,01 \cdot 5}{1}\right)=1156,52 \\
& \cdot \exp (-0,05)=1100,6
\end{aligned}
$$

This concentration value can also be found in Fig. 2, column V.

The calculation Eq. (49) has been hidden for 31 years and is left to the public to solve this puzzling algorithm. Its development is described in Schenk (2018b).

The course of the solution to this is shown in Fig. 4. According to e) and i), no deposition should take place,

\section{Stationary solution as a second option according to the task}

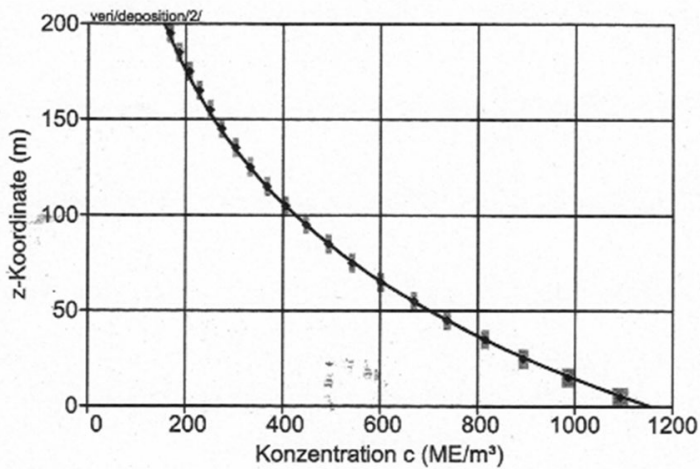

Bild 7: Vertikalprofil der Konzentration bei Sedimentation mit $v_{n}=0,01 \mathrm{~m} / \mathrm{s}$ und ohne Deposition. Die Turbulenz ist homogen $\left(K=1 \mathrm{~m}^{2} / \mathrm{s}\right)$. Die durchgezogene Kurve ist der theoretische Verlauf nach Gleichung (4.5) für $F_{c}=0$. Die über die gesamte Höhe gemittelte Konzentration hat den Wert von $500 \mathrm{ME} / \mathrm{m}^{3}$.

Fig. 4 Pollutant particles are speculatively redistributed by the authors of AUSTAL 
but this contradicts the course of the solution function. Because of the negative concentration gradient, there is a conductive mass transfer on the ground towards the free atmosphere.

Equation (20) can be used to show that the physics of the authors of AUSTAL prevent mass conservation. The soil concentration is $c_{0}=1100,6$, and the concentration at the upper boundary of the study area is calculated according to Eqs. (25) and (50), $c_{h}=148,95$.

$$
\begin{aligned}
c_{h}= & c_{0} \cdot \exp \left(-h \cdot \frac{v_{s}}{K}\right)+\frac{F_{c}}{v_{s}} \\
& \cdot\left[1-\exp \left(-h \cdot \frac{v_{s}}{K}\right)\right] \\
= & 1100,6 \cdot \exp \left(-200 \cdot \frac{0,01}{1}\right)+\frac{0}{0,01} \\
& \cdot\left[1-\exp \left(-200 \cdot \frac{0,01}{1}\right)\right]=148,95
\end{aligned}
$$

The concentration gradient at the upper limit is.

$$
\begin{aligned}
\frac{\partial c}{\partial z}(h)= & \frac{1}{K} \cdot \exp \left(-\frac{v_{s}}{K} \cdot h\right) \cdot\left(F_{c}-c_{0} \cdot v_{s}\right) \\
= & \frac{1}{1} \cdot \exp \left(-\frac{0,01}{1} \cdot 200\right) \\
& \cdot(0-1100,6 \cdot 0,01)=-1,48
\end{aligned}
$$

to $\partial c / \partial z(h)=-1,48$ according to Eqs. (35) and (51). With further parameters according to $h$ ) and i) of the task, the mass balance (52).

$$
\begin{array}{llll}
v_{s} \cdot c_{0} & -v_{s} \cdot c_{h} & +v_{d} \cdot c_{0} & -K \cdot \frac{\partial c}{\partial z}(\mathrm{~h})=0 \\
0,01 \cdot 1100,6 & -0,01 \cdot 148,9 & +0 \cdot 1100,6 & +1 \cdot 1,489 \neq 0
\end{array} .
$$

a) "The emission is continuous at $1 \mathrm{~g} / \mathrm{s}$ ".

b) The simulation is completed on the "10th day" with $t=240 \mathrm{~h}$.

c) The size of the control volume is specified with the geometric lengths $L_{x}=1000, L_{y}=1000$ and $L_{z}=200$.

d) The sedimentation and deposition rate are $v_{d}=0,05$ and $v_{s}=0,05$. The diffusion coefficient is $K=1$.

e) There is a "mass flow density forced by the source", $F_{c}=Q=1$.

f) The source is at an altitude of $h[m]=200$.

g) One calculates a "time series over 10 days". is obtained with Eq. (20). The mass conservation law is violated.

Taking into account Eqs. (36) and (6), $\dot{m}^{A}=\dot{m}^{B}$, Eq. (53).

$$
\begin{aligned}
\dot{m}^{B} & =-K \cdot \frac{\partial c}{\partial z}(0)=-\left(F_{c}-c_{0} \cdot v_{s}\right) \\
& =-(0-1100,6 \cdot 0,01)=11,006,
\end{aligned}
$$

results for the calculation of the deposition current. Then there is a conductive mass transfer, $\dot{m}^{B}=11,006$. However, the AUSTAL authors stipulate that no deposition should take place after e) and i), $F_{c}=0$. This contradiction can only be clarified in such a way that one would have to assume that the diffusion coefficient would be identical to zero, $K=0$ or, on the other hand, that despite an existing potential gradient, $\partial c / \partial z(0) \neq 0$, it would be
According to $\mathrm{f}$ ) the area source is at a height of $h=200$. As described under e), the emission takes place through a "mass flow density forced by the source" with $F_{c}=1$. According to b) and g) the task is again based on a non-stationary approach. In contrast, the AUSTAL authors only carry out stationary examinations. Algorithms and solution functions for non-stationary examinations are also unknown here. The AUSTAL authors relate their calculations to the validity of the differential Eq. (3) and use the wrong solution functions (25) and (26). In order to gain certainty about the validity of all approaches, non-stationary and stationary simulations are also carried out here and the results compared with Janicke's solutions.

Correct non-stationary and stationary solution taking into account the Berljand boundary condition according to Schenk (2018b) 


\section{2b Depositionstest: Deposition mit Sedimentation}

Mit $v_{d}=v_{s}$ erhält man in Gleichung (26) eine konstante Konzentrationsverteilung. Bei einer Quellstärke von $1 \mu \mathrm{g} /\left(\mathrm{m}^{2} \cdot \mathrm{s}\right)$ und $v_{\mathrm{d}}=0,05$ beträgt der Konzentrationswert $20 \mu \mathrm{g} / \mathrm{m}^{3}$.

$\begin{array}{rrrrr}\text { K } & \text { Cmin } & \text { C } & \text { Cmax } & \text { Csol1 } \\ \text { I } 1 & \text { II } 19.4 & \text { I } 20.3 & \mathrm{~N}^{21.2} & V^{20.0} \\ 2 & 19.6 & 20.6 & 21.6 & 20.0 \\ 3 & 19.6 & 20.8 & 22.0 & 20.0 \\ 4 & 19.8 & 21.1 & 22.4 & 20.0 \\ 5 & 20.8 & 22.2 & 23.6 & 20.0 \\ 6 & 19.9 & 21.2 & 22.5 & 20.0 \\ 7 & 19.5 & 20.8 & 22.1 & 20.0 \\ 8 & 19.5 & 20.9 & 22.3 & 20.0 \\ 9 & 19.2 & 20.6 & 22.0 & 20.0 \\ 10 & 19.2 & 20.6 & 22.0 & 20.0 \\ 11 & 18.8 & 20.1 & 21.4 & 20.0 \\ 12 & 18.5 & 19.7 & 20.9 & 20.0 \\ 13 & 18.9 & 20.2 & 21.5 & 20.0 \\ 14 & 18.5 & 19.7 & 20.9 & 20.0 \\ 15 & 19.4 & 20.6 & 21.8 & 20.0 \\ 16 & 19.3 & 20.5 & 21.7 & 20.0 \\ 17 & 19.1 & 20.2 & 21.3 & 20.0 \\ 18 & 19.4 & 20.5 & 21.6 & 20.0 \\ 19 & 19.3 & 20.5 & 21.7 & 20.0 \\ 20 & 19.3 & 20.5 & 21.7 & 20.0\end{array}$

Rechengebiet: $1000 \times 1000 \times 200 \mathrm{~m}^{3}$, aufgeteilt in $1 \times 1 \times 20$ Maschen (vertikal äqudistant) mit periodischen Randbedingungen.

Meteorologie: Homogene Turbulenz mit ua $=0,2$, $z 0=0,08$ und "Blm=0,1;SW=0.5; Tau=2; $v_{\mathrm{N}}=0,05$, $v_{\mathrm{s}}=0,05 ;$ Us $=0,2$; "Zeitreihe über 10 Tage.

Quelle: Flächequelle in $200 \mathrm{~m}$ Höhe. Die Emission erfolgt kontinuierlich mit $1 \mathrm{~g} / \mathrm{s}$ und Rate $=0,01$; es werden also 864 Partikel pro Tag freigesetzt.

Die nebenstehende Tabelle enthält für den 10ten Tag das Vertikalprofil (Index K) der Konzentration (Spalte C). Aus dem vom Programm ausgewiesenen Stichprobenfehler, der hier zwischen $2 \%$ und $4 \%$ liegt, sind die untere Grenze (Spalte Cmin)

und obere Grenze (Spalte Cmax) des 95-Prozent-Vertrauensintervalls gebildet. Die Spalte Csoll enthält den theoretischen Wert $20 \mu \mathrm{g} / \mathrm{m}^{3}$. In einem Fall liegt der Wert außerhalb des Vertrauensintervall.

Fig. 5 Task of the AUSTAL authors "Deposition with Sedimentation"

\section{First option, non-stationary consideration}

According to the first option, it is a non-stationary task, which is described by the differential Eqs. (2) with the initial condition (12) $c_{A}=0$. Analytical solutions are not available for this, which is why the solution method according to Schenk (1980) was used here.

The results for this are shown in Fig. 6 with the graphs $\mathrm{A}$ and $\mathrm{B}$. The deposition and sedimentation speed as well as the diffusion coefficient are specified according to d) the task. The source height is taken into account according to $\mathrm{f}$ ) and is at a height of $200 \mathrm{~m}$. At the lower boundary, the Berljand boundary condition according to Eq. (10) was fulfilled. At the upper limit, it was assumed that pollutant concentrations can no longer be measured at a sufficiently high level, $c_{H}=c(H)=0$. So that the height of the source can be included with sufficient accuracy, the height of the study area was increased from to $H[m]=400$. In graph $\mathrm{A}$, the temporal development of the concentration distribution in the interval $0 \leq t \leq T_{E}$ was evaluated. After a simulation time of $T_{E}=2,6 \mathrm{~h}$ the stationary solution is reached. The maximum concentration at source height is $c_{h}=c(200) \approx 20$ and the soil concentration is $c_{0} \approx 10$. The error deviation $\varepsilon=\left|c_{A n}-c(2,6 h)\right| / c_{A n} \cdot 100[\%]$ compared to analytical solutions is below $\varepsilon<0,1$. The analytical solution is to be understood under $c_{A n}\left[\mu g / m^{3}\right]$.

High demands are placed on reference solutions. The mass consistency must be demonstrated for all simulation times. For this purpose, all required balance 
sheet quantities according to Eq. (18) must be carried along during the calculation. These include the production term $\int \partial c / \partial t \cdot d z$, the convective and conductive material flows at the boundary surfaces $v_{s} \cdot c_{0}, v_{s} \cdot c_{H}, v_{d} \cdot c_{0}$ und $\mathrm{K} \cdot \partial \mathrm{c} / \partial \mathrm{z}(\mathrm{H})$ as well as the source term $Q=F_{c}=\int \dot{q} \cdot d z=1$ according to Eqs. (19) and e). These terms were determined numerically as a function of time and their course is shown graphically in graphic B in Fig. 6.

The integral Eq. (54)
In the stationary case, Eqs. (21) and (22) must be assumed. First, the soil concentration is calculated according to Eq. (56).

$$
c_{0}=\frac{Q}{\left(v_{s}+v_{d}\right)}=\frac{1}{(0,05+0,05)}=10
$$

with the information on d) and e). Equation (57) gives the maximum concentration $c_{h}=20$ at source height $h=200$.

$$
\begin{aligned}
& \text { X) } \int_{0}^{H} \frac{\partial c}{\partial t} \cdot d z+v_{s} \cdot c_{0}-v_{s} \cdot c_{H}+v_{d} \cdot c_{0}-K \cdot \frac{\partial c}{\partial z}(\mathrm{H})-\int_{0}^{H} \dot{q} \cdot d z=0 \\
& \text { Y) } 5,32 \mathrm{E}-01+2,31 \mathrm{E}-01-0,05 \cdot 0+2,31 \mathrm{E}-01+2,58 \mathrm{E}-05-1 \quad \approx 0 \\
& \text { Z) } 1,75 \mathrm{E}-02+4,85 \mathrm{E}-01-0,05 \cdot 0+4,85 \mathrm{E}-01+4,94 \mathrm{E}-05-1 \quad \approx 0
\end{aligned}
$$

explains an exemplary numerical evaluation of the mass balance (18) for two different simulation times. In it, X) describe the integral mass balance (18) and Y) and Z) the evaluation at real time $t=1,16 \mathrm{~h}$ and $t=2,60 \mathrm{~h}$. The steady state is reached approximately after $t=2,60 \mathrm{~h}$ and not only after 10 days, as the AUSTAL authors claim.

The mass conservation law is fulfilled.

Because of $\partial c / \partial z(0, t) \neq 0$ according to Fig. 6, graphic $\mathrm{A}$, the deposition current is non-zero at all simulation times, $\dot{m}^{B}(t)=-K \cdot \partial c / \partial z(0, t) \neq 0$. For $t \rightarrow \infty$ one obtains a concentration distribution that does not change over time. It is approximately identical to the later stationary solution according to Eq. (24) if it is transformed according to $-K \cdot \partial c / \partial z(0)$. This gives Eq. (55).

$$
\begin{aligned}
& \dot{m}^{B}(z=0, t \rightarrow \infty)=-K \cdot \frac{\partial c}{\partial z}(0) \\
& \cong-c_{0} \cdot v_{d} \cdot \exp \left(-\frac{v_{s}}{K} \cdot z\right)=-10 \cdot 0,05 \\
& \cdot \exp \left(-\frac{0,01}{1} \cdot 0\right)=-0,5 .
\end{aligned}
$$

In the stationary case, $t \rightarrow \infty$, Eqs. (55) and (60) are identical. The deposition current $\dot{m}^{B}<0$ is directed against the positive potential gradient $\partial c / \partial z(0)>0$ at all simulation times. The second law of thermodynamics is fulfilled.

Second option, stationary viewing

$$
\begin{array}{lllll}
v_{s} \cdot c_{0} & -v_{s} \cdot c_{h} & +v_{d} \cdot c_{0} & -K \cdot \frac{\partial c}{\partial z}(\mathrm{~h}) & =0 \\
0,05 \cdot 10 & -0,05 \cdot 20 & +0,05 \cdot 10 & -1 \cdot 2,27 \cdot 10^{-5} \approx 0
\end{array}
$$

$$
\begin{aligned}
c_{h}= & c(200)=c_{0} \cdot \frac{v_{s}+v_{d}}{v_{s}} \\
& \cdot\left[1-\frac{v_{d}}{v_{s}+v_{d}} \cdot \exp \left(-\frac{v_{s}}{K} \cdot 200\right)\right] . \\
= & 10 \cdot \frac{0,05+0,05}{0,05} \\
& \cdot\left[1-\frac{0,05}{0,05} \cdot \exp \left(-\frac{0,05}{1} \cdot 200\right)\right]=20
\end{aligned}
$$

The concentration curve calculated with this equation can be seen in the graph $\mathrm{C}$ of Fig. 6 . The excellent agreement between the analytical and numerical solution in the scope $z \leq 200$, which was achieved with the Schenk (1980) method, should be emphasized.

Here too it must be demonstrated that the mass conservation law is fulfilled. The integral Eq. (20) is again responsible. Approximately, no convective material flow is observed at the upper limit of the investigation area for $h=200$ according to Eq. (23), which is proven with Eq. (58).

$$
\begin{aligned}
K \cdot \frac{\partial c}{\partial z}(h) & =v_{d} \cdot c_{0} \cdot \exp \left(-\frac{v_{s}}{K} \cdot h\right) \\
& =0,05 \cdot 10 \cdot \exp \left(-\frac{0,05}{1} \cdot 200\right) \\
& =2,27 \mathrm{E}-05 \approx 0
\end{aligned}
$$

In addition, the specification $v_{s}=0,05$ according to $\mathrm{d}$ ) must be observed 


\section{Non-stationary solution as the first option}

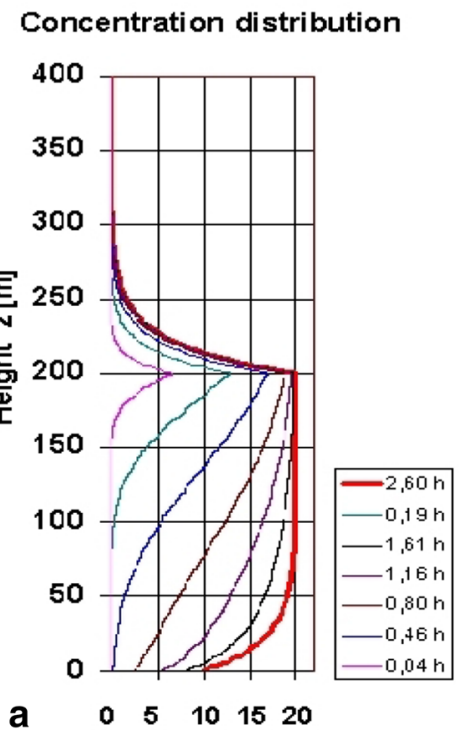

Concentration $\mathrm{c}\left[\mathrm{\mu g} / \mathrm{m}^{3}\right]$

Integral mass balance

Simulation time $t=1,16 \mathrm{~h}$

Simulation time $\mathrm{t}=\mathbf{2}, \mathbf{6 0} \mathrm{h}$
Integral mass balance

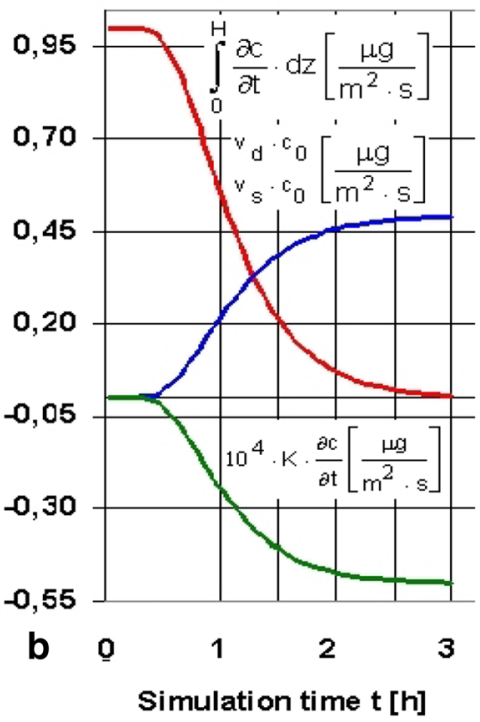

\section{Stationary solution as a} second option

Concentration distribution

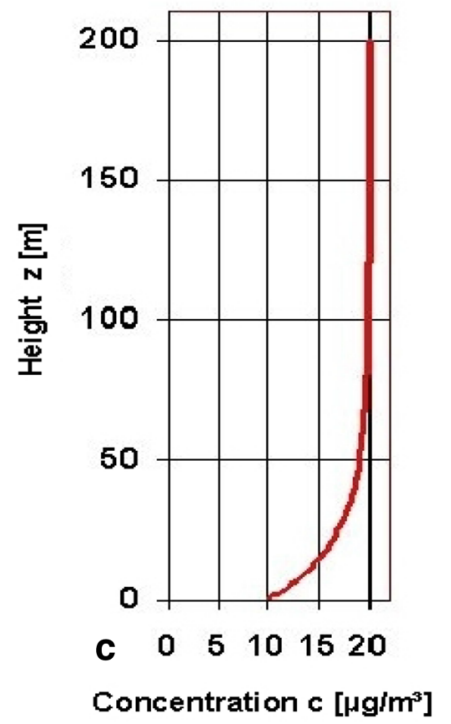

Fig. 6 Correct stationary and unsteady solution for the spreading case "Sedimentation with Deposition"

The balance Eq. (59) proves that constant mass is guaranteed.

Equation (23) gives the relationship (60)

$$
\begin{aligned}
\dot{m}^{B} & =-K \cdot \frac{\partial c}{\partial z}(0)=-c_{0} \cdot v_{d} \cdot \exp \left(-\frac{v_{s}}{K} \cdot z\right) \\
& =-10 \cdot 0,05 \cdot \exp \left(-\frac{0,01}{1} \cdot 0\right)=-0,5 .
\end{aligned}
$$

Then there is a conductive mass transfer, $\dot{m}^{B}=-0,5$. Deposition should take place after $(\mathrm{e}), F_{c} \neq 0$. Due to an existing potential gradient $\partial c / \partial z(0) \neq 0$ there is also a deposition, $\dot{m}^{B}=-K \cdot \partial c / \partial z(0) \neq 0$. The second law is the thermodynamics is fulfilled.

Faulty non-stationary and stationary solution taking into account the Janick's Convention according to Trukenmüller et al. (2015)

\section{First option, non-stationary consideration}

Again, according to b) and g) of the task, it must be assumed that the AUSTAL authors considered non-stationary conditions. However, no solution algorithms and concentration profiles are given for this. The AUSTAL authors did not perform non-stationary calculations.

$$
\begin{gathered}
\int_{0}^{h} \frac{\partial c}{\partial t} \cdot d z+v_{s} \cdot c_{0}-v_{s} \cdot c_{h}+v_{d} \cdot c_{0} \\
-K \cdot \frac{\partial c}{\partial z}(\mathrm{~h})-\int_{0}^{h} \dot{q} \cdot d z=0
\end{gathered}
$$

Due to the lack of non-stationary solution courses, the integral Eq. (18) cannot be used to control mass conservation. The AUSTAL authors do not provide any simulation results. If the authors of AUSTAL state that a stationary solution would have appeared after 10 days, the public will be deceived as well.

Second option, stationary viewing

The AUSTAL authors only provide stationary solutions for this task. To do this, they use their incorrect solutions (25) and (26). Using Eq. (26), $F_{c}=v_{d} \cdot c_{0}$, one calculates the soil concentration according to Eq. (62). 


$$
c_{0}=\frac{F_{c}}{v_{d}}=\frac{1}{0,05}=20
$$

and with Eq. (25) a constant concentration distribution in the entire study area from $c(z)=20=$ const. according to Eq. (63).

$$
\begin{aligned}
c(z)= & c_{0} \cdot \exp \left(-z \cdot \frac{v_{s}}{K}\right)+\frac{F_{c}}{v_{s}} \cdot\left[1-\exp \left(-z \cdot \frac{v_{s}}{K}\right)\right] \\
= & c_{0} \cdot \exp \left(-z \cdot \frac{v_{s}}{K}\right)+\frac{0,05 \cdot c_{0}}{0,05} \\
& \cdot\left[1-\exp \left(-z \cdot \frac{v_{s}}{K}\right)\right]=c_{0}=20
\end{aligned} .
$$

The result of this calculation is shown in Fig. 7. In contrast to the correct solution with $c_{0}=10$, the authors of AUSTAL calculate the wrong concentration distribution in the amount of $c(z)=20=$ const.. This untrue result is also highlighted in column $\mathrm{V}$ of Fig. 5. As can be seen with the specification $\mathrm{f}$ ), a source should have been in 200 m, which, however, contrary to Fig. 6, Graph C, cannot be seen in Fig. 7 of the AUSTAL authors.

It can easily be demonstrated that Eq. (25) is an incorrect solution of differential Eq. (3). For this purpose, Eq. (20) is used again. With the simulation results already described and taking into account Eq. (36), $\partial c / \partial z(h) \sim\left(F_{c}-c_{0} \cdot v_{s}\right)=1-20 \cdot 0,05=0$, the expres$\operatorname{sion}(64)$.

$$
\begin{array}{llll}
v_{s} \cdot c_{0} & -v_{s} \cdot c_{h} & +v_{d} \cdot c_{0} & -K \cdot \frac{\partial c}{\partial z}(\mathrm{~h})=0 \\
0,05 \cdot 20 & -0,05 \cdot 20 & +0,05 \cdot 20 & -1 \cdot 0
\end{array}
$$

results. The mass conservation law is therefore also violated for the "sedimentation with deposition" propagation case.

Equation (6), $\dot{m}^{A}=\dot{m}^{B}$, can be used to prove that the second law of thermodynamics is also violated. Equation (36).

$$
K \cdot \frac{\partial c}{\partial z}(0)=\left(F_{c}-c_{0} \cdot v_{s}\right)=(1-20 \cdot 0,05) \equiv 0
$$

is required to calculate the conductive current. The deposition current

$$
\dot{m}^{B}=-K \cdot \frac{\partial c}{\partial z}(0)=-\left(F_{c}-c_{0} \cdot v_{s}\right)=-(1-20 \cdot 0,05)=0 .
$$

is calculated using Eq. (65).

After that, there is no conductive mass transfer. However, the authors of AUSTAL state that deposition should take place after e), $F_{c} \neq 0$. This contradiction can only be clarified in such a way that one would
Stationary solution as a second option according to the task

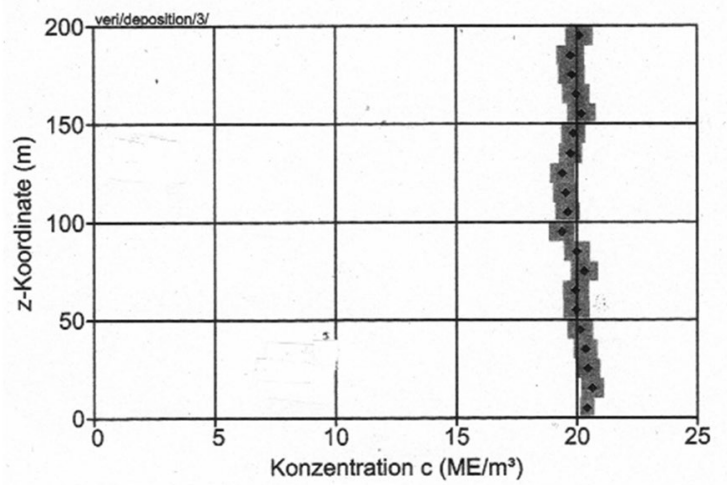

Bild 8: Vertikalprofil der Konzentration bei Deposition mit $v_{d}=0,05 \mathrm{~m} / \mathrm{s}$ und Sedimentation mit $v_{s}=0,05 \mathrm{~m} / \mathrm{s}$. Die Quelle bei $z=200 \mathrm{~m}$ emittiert konstant und erzwingt eine Massenstromdichte $F_{c}=1 \mathrm{ME} /\left(\mathrm{m}^{2} \cdot \mathrm{s}\right)$. Der theoretische Wert der Konzentration $c(z)=20 \mathrm{ME} / \mathrm{m}^{3}$

Fig. 7 The concentration distribution shows that no deposition can take place

have to assume that the diffusion coefficient would strive towards infinity, $K \rightarrow \infty$. On the other hand, contrary to $\dot{m}^{B}=-K \cdot \partial c / \partial z(0)$, the material flow would follow a non-existent potential gradient $\partial c / \partial z(0)=0$. The first case is excluded because the diffusion coefficient is a finite material parameter. The second case is correct and justified. Therefore the second law of thermodynamics is violated. If contradicted, the pollutant particles would have to be contrary to Fick's law according to Häfner et al. (1992) that the concentration gradient at the bottom is not equal to zero, $\partial c / \partial z(0) \neq 0$.

\section{Homogeneity tests}

Assessment of the tasks In order to derive reference solutions for homogeneity, the AUSTAL authors describe the so-called "Homogeneous turbulence, constant step size, "Homogeneous turbulence, variable step size", so-called "Inhomogeneous turbulence, constant step size" and "Inhomogeneous turbulence" variable step size" as four separate test cases. However, as will be shown, all these test cases can be traced back to a single trivial task and solution. The model parameters for all tasks are given uniformly with a) to g).

The tasks of the AUSTAL authors are described in graphs A to D in Fig. 8. The only difference is that in the two cases of so-called "Homogeneous turbulence", the conductive transport is described by a constant. In the two other examples of so-called "Inhomogeneous turbulence", location-dependent diffusion is used. As already described in the other cases of sedimentation and deposition, the authors of AUSTAL consider a), b) and c) a 
non-stationary approach here. While one pretends to carry out three-dimensional calculations, in all four cases one considers only a zero-dimensional spread with the time coordinate as the only variable. The task therefore describes the filling of any container with different media.

A special mention deserves the specification e) "Volume source distributed over the entire computing area". It is identical to the specification $\mathrm{f}$ ) of the task "sedimation without deposition". The tasks were taken from the Janicke (2002) reference. The results can be found in the publication Janicke (2000).

a) "The emission occurs only in the first hour of the first day", which means $T_{E}=3600$.

b) The simulation is completed on the "10th day" with $t=240 \mathrm{~h}$.

c) One calculates a "time series over 10 days".

d) The size of the control volume is specified with the geometric lengths $L_{x}=1000, L_{y}=1000$ and $L_{z}=200$. e) "Volume source distributed over the entire computing area".

f) "The total emission is $100 \mathrm{~kg}$.

g) "The mean concentration is $\bar{c}=500$ ".

Validation Non-stationary propagation processes are described by the differential Eq. (2). With the described model parameters, the Eq. (67).

$$
\frac{\partial c}{\partial t}-v_{s} \frac{\partial c}{\partial z}=\frac{\partial K_{z z}(z)}{\partial z} \cdot \frac{\partial c}{\partial z}+K_{z z}(z) \cdot \frac{\partial^{2} c}{\partial z^{2}}+\dot{q}(t)
$$

results, whereby $K_{z z}(z)\left[\mathrm{m}^{2} / \mathrm{s}\right]$ is to be understood here as the approach for describing the so-called "Homogeneous turbulence" or the so-called "Inhomogeneous turbulence". In the case of so-called "Homogeneous turbulence", $K_{z z}=$ const applies and in the case of so-called "Inhomogeneous turbulence", a dependency on z must be taken into account, $K_{z z}(z)$. It is therefore generally valid to replace the expression $K_{z z} \cdot \partial^{2} c / \partial z^{2}$ in the differential

\section{Homogeneous turbulence
Constant time step \\ a}

11 Homogenitätstest: Homogene Turbulenz, konstanter Zeitschritt

Wenn keine äußeren Kräfte wirken, solte sich in einem abgeschlossenen Rechengebiet bei einmaliger F reisetzung einer bestimmten Stoffmenge mit der Zeit eine konstante Korzentrationswerteilung e instellen.

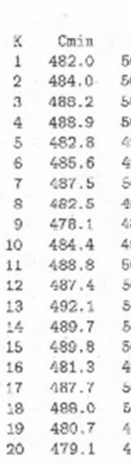

Rechengebiet: $1000 \times 1000 \times 200 \mathrm{~m}^{3}$, aufgeteilt in $1 \times 1 \times 20$ Maschen (vertikal äqudistant) mit periodischen Randbe-

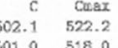

$\begin{array}{ll}502.1 & 522.2 \\ 501.0 \quad 518.0 \\ 503.3\end{array}$

$503.3 \quad 518.4$ $c=500 \mu \mathrm{gm}^{3}$ nur in einem von $20 \mathrm{~F}$ ällen $\mathrm{uf}^{3}$ llig aUßemalb der angegebenen Vertrauensintewalle liegt. Hier liegt er in keinem $F$ all außerhalb des Vertrauensintervalls

\section{Homogeneous turbulence}

\section{C}

\section{Variable time step}

12 Homogenitätstest: Homogene Turbulenz, variabler Zeitschritt

Diese Rechnung kann mit AUSTAI.2000 nicht durchgeführt werden, da der Zeitsetritt nicht explizit vorgebbar ist. Das Programm wählt bei homugener Turbulonz immer pinen konstanten Zeitschritt.

Fig. 8 Identical tasks for four supposedly different homogeneity tests

\section{Inhomogeneous turbulence Constant time step}

b

13 Homogenitätstest: Inhomogene Turbulenz, konstanter Zeitschritt

Wie Test 11, aber mit inhomogener Turbulenz.

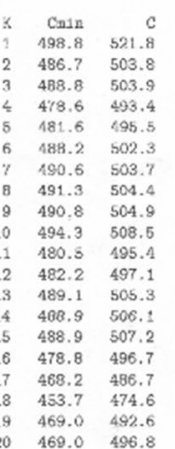

Rechengehiet: $1000 \times 1000 \times 200 \mathrm{~m}^{3}$, aufgeteilt in $1 \times 1 \times 20$ Cuar Maschen (vertikal äqudistant) mit periodischen Randbesingungen 520.9

Meteorologie: Inhomogene Turbulenz mit $u \approx=0,2$ $z 0=0,8, h a=1$ und "Blm=0,7; St=0,5 $S v=0,5, S w=0,5$ $\mathrm{Tau}=2, \mathrm{U} a=0,8$ ". Zeitre ihe über $10 \mathrm{Tage}$ 16.8 7.5

${ }_{7}$ Quelle: Volumenquelle über das gesamte Rechenge biet. Die Emission erfolgt nur in der ersten Stunde des ersten Tages. Bei Groupe $=36$. Rate 0,1 . bedeutet dies, daß jede Gruppe 10 Partikel enthätt. Die $G$ esamtemission ist $100 \mathrm{~kg}$ die mitt lere Konzentration also $500 \mu \mathrm{g} / \mathrm{m}^{\mathrm{F}}$

Aus dem vom Programm ausgewesenen stichprobe

(Spalte Cmin) und obere Grenze (Spalte Cmax) des $95 \%$ Vertrauensintervalls gebildet. Im statistischen Mittel ist zu erwarten, daß der korrekte Korzentrationswer $\mathrm{c}=500 \mu \mathrm{g} / \mathrm{m}^{3}$ nur in einem von $20 \mathrm{Fällen}$ zufälig außerhalb der angegebenen vertrauensintervalle liegt- Hier liegt er tatsächlich einmal außerhalb des Vertrauen sintervalls.

\section{d}

\section{Inhom ogeneous turbulence Variable time step}

14 Homogenitätstest: Inhomogene Turbnlenz, variabler Zcitschritt

Wie Test 11, uber mil inhonogeter Turbulenz und variablem 7eitschritt. 
Eq. (2) with $\partial / \partial z\left(K_{z z}(z) \cdot \partial c / \partial z\right)$, which results in Eq. (67).

In the case of so-called "Homogeneous turbulence", the authors of AUSTAL choose the simple approach to describe the effective diffusion (68).

$$
K_{z z}=1=\text { const }
$$

In a so-called "Inhomogeneous turbulence", the relationships (68), (70) and (71).

$$
\begin{aligned}
& \sigma_{w}(z)=0,5-0,4 \cdot \sin \left(\frac{z \cdot \pi}{2 \cdot h}\right), \\
& T_{w}(z)=1+20 \cdot \sin \left(\frac{z \cdot \pi}{2 \cdot h}\right), \\
& K_{z z}(z)=\left[\sigma_{w}(z)\right]^{2} \cdot T_{w}(z)
\end{aligned}
$$

are used. In these equations, $\sigma_{w}[\mathrm{~m} / \mathrm{s}]$ means the dispersion of wind speed fluctuations and $T_{w}[s]$ the Lagrangian correlation time. In connection with the solution of the differential Eq. (67), ultimately only the approach (71) is of interest.

In addition, it must be noted that after e) the task for all four cases for so-called homogeneity, a "volume source over the entire computing area" is assumed. However, this assumption means that the mass according to f) of $m_{E}=100$ with a concentration according to g) of $c(z)=\bar{c}=500=$ cons $\tan t$ fills the entire control volume evenly. This means that no changes in concentration can occur in the study area, which means $\partial c / \partial z=0$. If one looks at Eq. (67), the trivial relationship $\partial c / \partial t=\dot{q}(t)$ already results. According to a), the source term $\dot{q}(t)$ of Eq. (67) is constant over time for the time interval $0<\mathrm{t} \leq \mathrm{T}_{\mathrm{E}}=1 h, \dot{q}(t)=\dot{q}=$ const., and can be calculated according to Eqs. (72).

$$
\begin{aligned}
& \dot{q}=\frac{m_{E}}{V \cdot T_{E}}=\frac{100}{2 \cdot 10^{8} \cdot 3600} \cdot 10^{9}=0,139 \quad 0 \leq t \leq T_{E} \\
& \dot{q}=0 \quad \mathrm{t}>\mathrm{T}_{\mathrm{E}} .
\end{aligned}
$$

Equation (67) is simplified because of $\partial c / \partial x_{i}=\partial c / \partial z=0$ to Eq. (4), $d c / d t=\dot{q}$. A simple integration $c(t)=c_{A}+\int \dot{q} \cdot d t$ with the initial condition $c_{A}=0$ gives Eqs. (40) with the calculated value

$$
\begin{aligned}
\mathrm{c}(\mathrm{t}) & =\mathrm{c}_{\mathrm{A}}+\dot{q} \cdot t \\
\mathrm{c}\left(\mathrm{T}_{\mathrm{E}}\right) & =c_{A}+\dot{q} \cdot T_{E}=0+0,139 \cdot 3600 \approx 500 .
\end{aligned}
$$

Equation (73) is identical to Eq. (40) in the case of "sedimentation without deposition".

It can ultimately be seen that because of the disappearing concentration gradients, $\partial c / \partial z=0$, the relationships.
(68) for the calculation of a so-called homogeneous turbulence $K_{z z}$,

(69) to calculate a so-called speed fluctuation $\sigma_{w}$,

(70) to calculate the so-called Lagrangian correlation time $T_{w}$.

(71) to calculate a so-called inhomogeneous turbulence $K_{z z}(z)$ can have no influence on the course of the solution. The solution is independent of these parameters, which the AUSTAL authors did not recognize due to ignorance or which they intentionally concealed. It would be interesting to find out what the specialist guides have to say.

The correct solutions according to Eq. (73) are shown in Fig. 9. You can see the filling of the control room for the time intervals $0 \leq t[h] \leq 1$ and $1<t[$ Tage $] \leq 10$.

Contrary to the claims of the AUSTAL authors according to b) that the simulation should only be completed on the "10th day", the mean concentration of $\bar{c}=500$ is already reached after $1 \mathrm{~h}$. According to c), a "time series over 10 days" could not have been calculated. Here too, the solution (73) only describes zero-dimensional propagation with the time coordinate as the only independent variable for all four test cases.

This result can also only be compared with the filling of a container, which means that no dispersion models can be validated.

The results of the AUSTAL authors are explained in Fig. 10 with graphics A to D. With the correct solution according to Fig. 9 it turns out that all non-stationary simulation results of the authors of AUSTAL according to b) and c) are wrong. Non-stationary calculations have not taken place.

One specialty cannot be overlooked. The specification e) "Volume source distributed over the entire computing area" is not only applicable to all four homogeneity tests. It is also used for the trivial case of "sedimentation without deposition". Thus, the authors of AUSTAL provide five different reference solutions for one and the same task according to the differential Eq. (4) and the initial condition (12) according to Figs. 4 and 10.

a) "Sedimentation without deposition", Fig. 4,

b) "Homogeneous turbulence, constant time step", Fig. 10, Graph A,

c) "Inhomogeneous turbulence, constant time step", Fig. 10, Graph B,

d) "Homogeneous turbulence, variable time step", Fig. 10, Graph C,

e) "Inhomogeneous turbulence, variable time step", Fig. 10, Graph D, 


\section{Homogeneous and inhomogeneous turbulence}

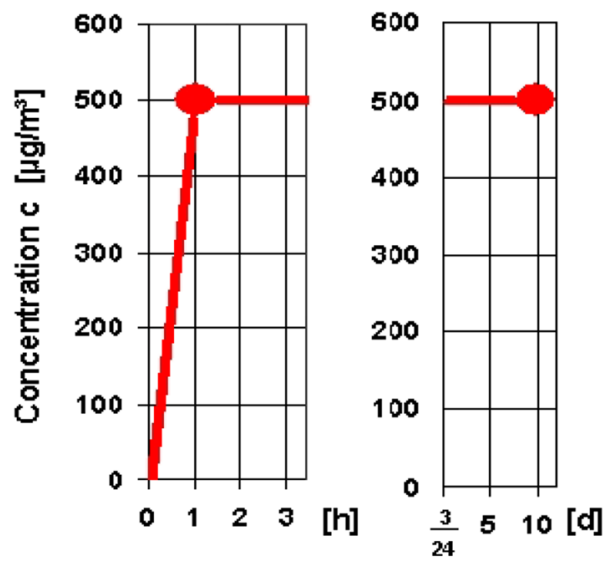

Simulation time $\mathbf{t}$

Fig. 9 The task of the AUSTAL authors trivially describes the filling of containers for all four case studies

However, they claim that there are different reference solutions. The publication by Janicke (2000) shows that the AUSTAL authors actually mean different solutions, where adventurous physical interpretations are given for each of the minor deviations. Different physics are faked.

\section{The analogy to the impulse-heat and mass transport}

Textbooks on physics and thermodynamics as well as process engineering like to refer to the existing analogy between the impulse, heat and mass transport. In the case of impulse, it is Newton's stress approach, $\tau=\eta \cdot \partial u / \partial z$. In the case of heat, it is Fourier's heat conduction, $N=-\lambda \cdot \partial \vartheta / \partial z$. In the case of admixtures, the analogy concerns Fick's law $\dot{m}^{B}=-K \cdot \partial c / \partial z$. This analogy is founded on these conductive approaches. The currents of impulses, energy and mass caused by them are collectively referred to as the conductive transport. Here it means $\tau\left[N / \mathrm{m}^{2}\right]$ the shear stress, $\eta[\mathrm{kg} /(\mathrm{m} \cdot \mathrm{s})]$ the dynamic toughness, $u[\mathrm{~m} / \mathrm{s}]$ the speed, $N\left[\mathrm{~W} / \mathrm{m}^{2}\right]$ the specific heat output, $\lambda[W /(m \cdot$ Kelvin $)]$ the thermal conductivity and $\vartheta[$ Kelvin] the temperature.

If one refers to the conductive material flow and considers the analogy to the heat flow, one would have to swap the concentration distribution with a temperature distribution in the case of "sedimentation without deposition" in Fig. 4 of the AUSTAL authors. After Fourier's heat conduction, a conductive heat flow takes place analogously to Eq. (53) from a higher temperature level in the direction of a lower ambient temperature. The authors of AUSTAL would now have to explain why, despite an analog negative temperature gradient $\partial \vartheta / \partial z<0$ and therefore analogously to $N>0$ und $\dot{m}^{B}>0$, there should be no analog heat flow $N \equiv 0$ und $\dot{m}^{B}=0$, It would then also have to be explained why, analogous to $F_{c}=0$ und $\mathrm{N}=0$, if there is no heat source, there is a heat flow according to Fig. 4. The second law of thermodynamics is violated.

In the case of "Deposition with sedimentation", the concentration would also have to be exchanged with the temperature in Fig. 7. After Fourier's heat conduction, there will then be no conductive heat flow analogous to Eq. (66). The authors of AUSTAL should now explain why, despite a disappearing analog temperature gradient $\partial \vartheta / \partial z=0$ and consequently analogous to $N=0$ und $\dot{m}^{B}=0$, an anologic heat flow $N \neq 0$ und $\dot{m}^{B} \neq 0$, should result towards the ground.

It should also be explained here why, analogously to $F_{c}=1$ und $\mathrm{N}=1$, despite the existing heat source, according to Fig. 7 there should be no heat flow at all. The second law of thermodynamics is violated.

If one considers the analogy to the impulse transport, the concentration distributions would have to be exchanged with flow velocities, from which the stress distributions in the fluid can be calculated. According to Schlichting (1964) there is a direct proportionality between stress and deformation. In the present case, however, the proportionality would be reversed. Tension and deformation are not the same here, but opposed. Newton's 3rd axiom is violated.

\section{The life stories of the AUSTAL dispersion model Preliminary remarks}

The author of this article takes a close look at the validity of all reference solutions given by the AUSTAL authors. He concludes that all physics and mathematics by the AUSTAL authors should be questioned. All doubts about credibility, honesty and scientific thoroughness deepen. This distrust was an occasion to investigate the life story and all the strange circumstances surrounding this model development. A true and elitist life story face each other.

\section{The real life story}

The real life story begins.

(1984) It is in Axenfeld et al. (1984) described a model for calculating dust precipitation. The theoretical basis is explained by a thought model. This defines the deposition speed as the speed after which "... a column standing on the surface of the earth, which contains the material capable of deposition, runs empty through deposition". Deposition means loss and not retention. However, the authors of AUSTAL are in prominent company with their opinion. So you can later e.g. also in Graedel et al. (1994), p. 144, learn that material capable of deposition is lost. 


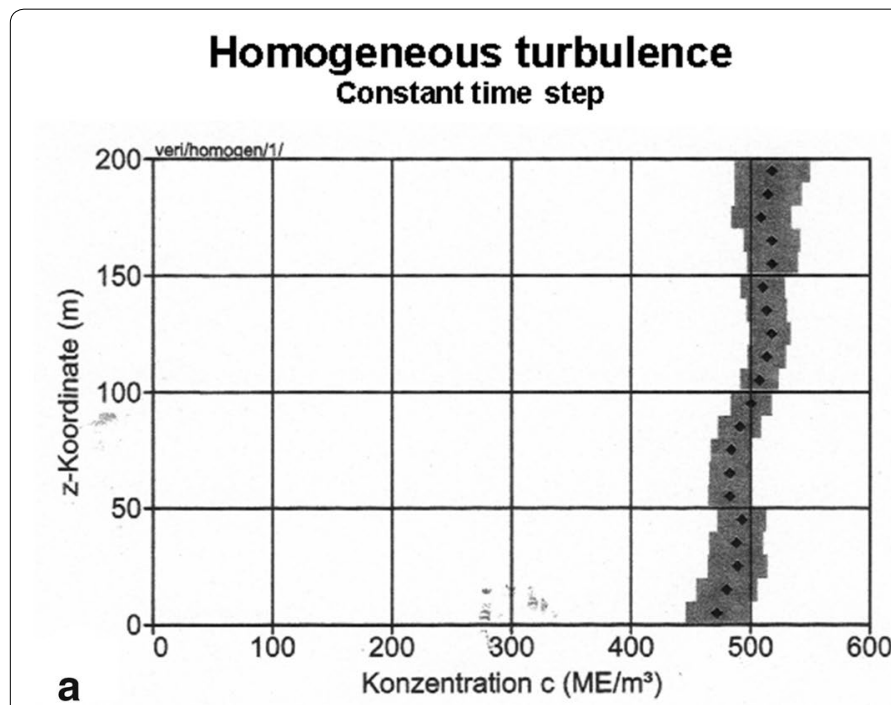

Bild 1: Vertikalprofil der Konzentration in einem abgeschlossenen Volumen bei homogener Turbulenz und konstantem Zeitschritt. Theoretisch solte die Konzentration überall den gleichen Wert $\mathrm{c}=500 \mathrm{ME} / \mathrm{m}^{3}$ be sitzen

\section{Homogeneous turbulence variable time step}

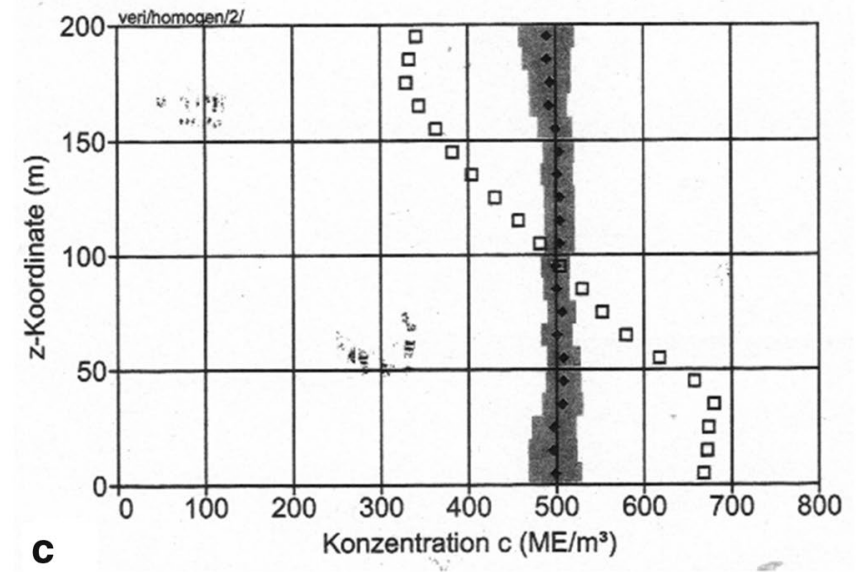

Bild 2: Vertikalprofil der Konzentration bei homogener Turbulenz und räumlich variablem Zeitschritt $(1<=T a u<=8)$. Die offenen Quadrate stammen aus einer Simulation, in der die Driftgeschmindigkeit willkürlich Null gesetzt wurde.

\section{Inhomogeneous turbulence} Constant time step

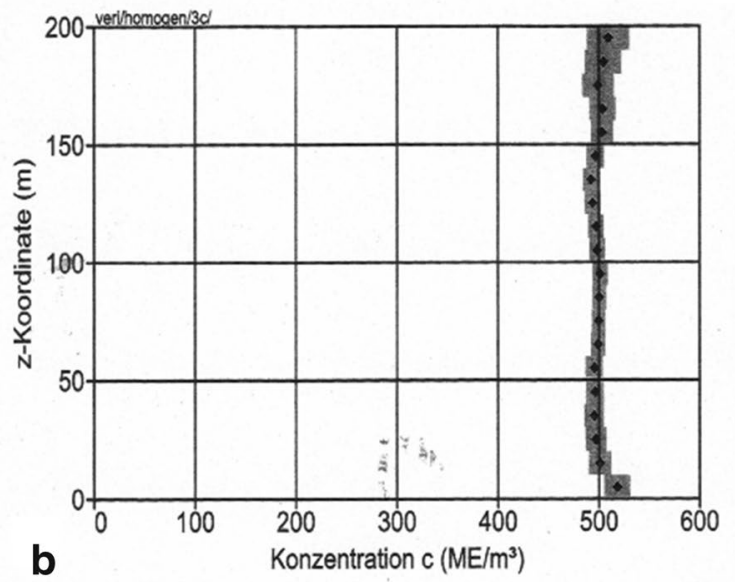

Bild 4: Vertikalprofil der Konzentration bei inhomogener Turbulenz (siehe Gleichung (4.1 bis (4.3)) und räumlich konstantem Zeitschritt Tau=2 Sekunden.

\section{Inhomogeneous turbulence variable time step}

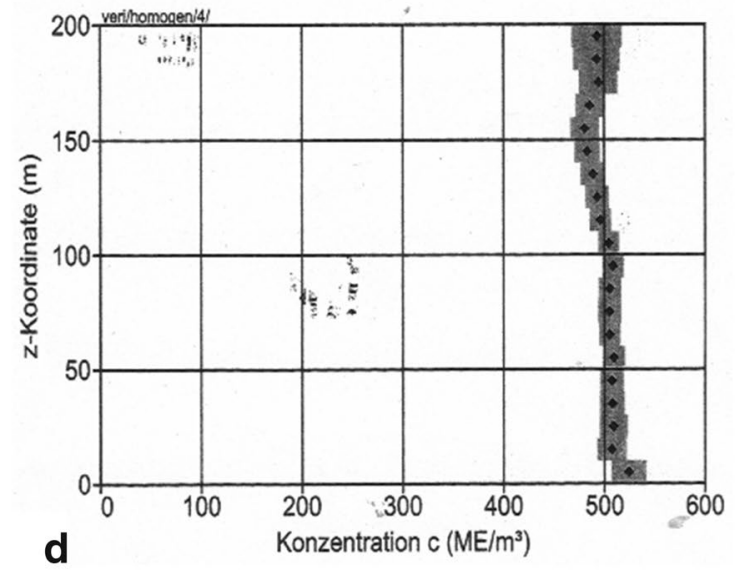

Bild 5: Vertikalprofil der Konzentration bei inhomogener Turbulenz (siehe Gleichung (4.1 bis (4.3)) und räumlich variablem Zeitschritt ( $2<=$ Tau $<=20$ ).

Fig. 10 The AUSTAL authors only provide stationary solutions, non-stationary bills have not taken place

You can read there "... deposition occurs when a gas molecule comes into contact with a surface and is lost on it".

(1988) with reference to Axenfeld et al. (1984) and by means of the Janicke Convention in VDI (1988) establish a new theory of the spread of air pollutants. The physics and mathematics of the AUSTAL authors are adopted without criticism.

(2001) this model is further developed in Janicke (2001) to the LASAT model. This dispersion model is later promisingly referred to as the "parent model" for all dispersion calculations.
(2002) is described by the authors Janicke et al. (2002) developed the "Model-Based Assessment System for Immission Control in Industry and Economy" called AUSTAL. The faulty algorithms for deposition and sedimentation by the authors of Axenfeld et al. (1984) not corrected.

(2009) Further development of AUSTAL to a model for the calculation of the spread of radionuclides for defense against nuclear-specific hazards LASAIR according to Janicke (2009). Ensuring security is an interdisciplinary task. Nuclear technicians, thermodynamics engineers, 
materials scientists, solid-state mechanics and, for example, fluid mechanics are responsible for the safety of their nuclear power plants. You can expect that efforts will also be made to protect citizens and protect the environment outside of nuclear power plants. They don't want their efforts to be frivolously gambled away.

(2011) Development of AUSTAL to calculate the spread of different substances according to TA Luft and odor spread according to Janicke et al. (2011). The substance-specific peculiarities of the spread of smells, e.g. have already been described in Westphal 1959 are not taken into account. The algorithms for this are unknown and remain unpublished. One only refers to source texts here, as if users should read the physics used from the source texts.

(2014) After the AUSTAL was published in BMU (2002), those responsible for pollution control and environmental engineers raised doubts about the validity of the AUSTAL reference solutions. In 2014, the author of this article was commissioned by the company WETSTKAL, United Warstein Limestone Industry, to develop expertise on this expansion model according to Schenk (2014). The author of this expertise comes to the conclusion that all reference solutions from AUSTAL violate mass conservation and the second law of thermodynamics. The use of critical terms also leads to the conclusion that the AUSTAL authors are not very familiar with the theory of modeling the spread of air pollutants. The results of this expertise are published in Schenk (2015a). They form the background of all criticism of the AUSTAL expansion model.

(2015) Further development of AUSTAL into a model called LASPORT for calculating the spread of airportspecific pollutants according to Janicke (2015). However, the spread of aviation pollutants generally requires a nonstationary view. The validation of time-dependent reference solutions is not considered necessary.

(2015), interested environmental engineers recognize the contradictions of different reference solutions. In Schenk (2015a) it is recognized for the first time in 31 years that all reference solutions are faulty. The mass conservation law and the second law of thermodynamics are violated. For example, the authors of AUSTAL are completely ridiculous with the claim that 3D wind fields can be validated with the rigid rotation of a solid in the plane.

(2015) contradict in Trukenmüller et al. (2015) 14 authors of all objections. The AUSTAL authors want to prove the opposite. But they rely more on the authority of their offices than on mathematics and mechanics. They are very convinced that they are publishing false reference solutions. The authors include sworn and non-committed experts, protagonists and expert advisors from
AUSTAL, office managers and administrative workers. The authors also include a nuclear optician with a doctorate in 1997, who, together with a plasma physicist, is one of the actual authors of AUSTAL. How they obtained the required basic knowledge in the field of coupled impulse, heat and mass transport to model the spread of air pollutants is unknown.

(2015) With the wording "As a closer analysis shows, the results of AUSTAL2000 are correct, while the contradictions highlighted by R. Schenk are based on fundamental errors in his evidence..." published the Federal Environment Agency Dessau Roßlau according to UBA (2015a) his website publicly false reports.

(2015) In Schenk (2015b) the author deals with the explanations in Trukenmüller et al. (2015). The errors of all described reference solutions are analyzed. The correct reference solutions and derivation are given.

(2015) The publication Schenk (2015a) is obviously viewed as an industrial accident. A new editorial team will be appointed for the magazine IMMISSIONSCHUTZ at the end of the year. The area of spreading air pollutants will be filled with an office worker for meteorology. With regard to the AUSTAL topic, the editorial team announced immediately after the new appointment that "the space that this technical discussion had taken up in the magazine was more than exhausted". Later it is communicated again that "the discourse on AUSTAL2000 has ended from the editorial point of view". However, no claim is made that this castling is intended to intentionally prevent further occupational accidents.

(2016) In reply to Schenk (2015b) all criticism is rejected in Trukenmüller (2016). With differently defined deposition speeds, the aim is to achieve equivalence of the reference solutions from AUSTAL to Schenk (2015b). With little physics, attempts are made to prove the correctness of one's own reference solutions. Trukenmüller (2016) turns out to be a smooth delusion.

(2017), finally, Trukenmüller (2017) again contests all of the objections justified in Schenk (2015b). The Janicke Convention is universal and, for example, by Venkatram et al. (1999) justified. In the absence of physical insight, reference is made to the authority of other scientists. You would also use Janicke's Convention, but this is not true. The author of this article is asked to agree with the incorrect views on sedimentation and deposition. One uses the reputation of 20 internationally recognized and esteemed authors in the field of modeling and spreading, sedimentation and deposition and hides their own ignorance behind it.

(2017) The authors of AUSTAL publish in Janicke et al. (2017) under the heading "Precise numerical solution and analytical approximation for the wind profile over flat terrain" an attempt to validate AUSTAL with a wind field. 
The AUSTAL authors obviously want to react to the criticism in Schenk (2015a), but they prove that they did not understand the difference between numerical and analytical solutions in 2017 either. The opposite is true. Numerical algorithms describe approximate solutions and not vice versa analytical methods.

(2018) Schenk (2018b) deals with the results of Venkatram et al. (1999). It is true that the authors of Venkatram et al. (1999) are more concerned with deriving analytical relationships between deposition and sedimentation speeds than with explaining any conventions.

(2020) the AUSTAL authors send the deception Trukenmüller (2016) to administrative offices and offices of the Federal Republic of Germany on request. They abuse the authority of their office and position.

The true life story is a teaching example of how truths could be suppressed for 36 years from 1984 to 2020.

\section{The elite life story of the AUSTAL authors}

The authors of AUSTAL write the other life story according to UBA (2018) themselves and explain how their model of expansion came about.

"The history of AUSTAL2000 started almost exactly 21 years ago. At the NATO-CCMS conference in San Francisco at the end of August 1981, I had just presented my approach to Lagrangian modeling in inhomogeneous turbulence, at the same time as the corresponding work by Wilson and Legg \& Raupach, and thus fulfilled a promise that I made on Hanna Had given last year's conference in Amsterdam. Preparations for TA Luft 1983 were still going on, but the parties involved were already considering how to proceed with TA Luft in the medium and long term. So after the conference, we sat down in the small town of Kirkwood, in the mountains east of Jackson, to summarize our ideas for a concept in a workshop (as part of the UBA project "Handbook of Immission Forecasting”). these were: Werner Klug, Paul Lühring, Rainer Stern, Robert Yamartino and I. The key points of the long-term concept, which should extend 5 to 7 years into the future, included:... After 21 years now, with the new TA Luft, that on October 1st, 2002, key points of the concept realized at that time, maybe you should meet again in the mountains to think about how the TA Luft expansion model would have to be developed in the next 20 years', Lutz Janicke am September 30, 2002".

Unquestionably, you present yourself inflated in public.

\section{Summary and discussion of the results}

The author of this article deals with the faulty algorithms of the AUSTAL dispersion model. Since 2002, according to VDI 3945 Part 3 (2000), this expansion model with its reference solutions has been declared binding for all model development in the Federal Republic of Germany.
Other model developments have to prove their equivalence on the fixed reference solutions. Because of the high public importance attached to this model of expansion, the discussion of its physical and mathematical foundations is justified. Every effort is justified. The public should also be involved.

\section{Berljand's boundary condition}

Initially, this article explains in detail the initial boundary value output for the description of the spread of air pollutants. It consists of the mass transfer Eq. (1), the initial condition (12) and Berljand's boundary conditions (10). Because of the general validity for all stationary and non-stationary tasks of impulse, heat and mass transport, this boundary condition according to Fig. 1 is derived in detail. It can thus be used for all tasks of the AUSTAL authors to derive the reference solutions.

\section{Integral sentences}

In Schenk (2015a) the accusation is raised that all reference solutions by the authors of AUSTAL violate the mass conservation law and the second law of thermodynamics. The general validity of these allegations is demonstrated in Schenk (2015b), which is heavily disputed in Trukenmüller (2017). For this reason, the author of this article develops the integral Eqs. (18) and (20), which are directly applied to all individual cases of the reference solutions. The validity of the second law of thermodynamics can also be checked.

\section{Reference solutions}

On the basis of the initial boundary value task described and taking Berljand's boundary condition into account, the correct solutions according to Eqs. (21) and (22) are compared with the incorrect reference solutions (25) and (26). The defective Janicke Convention (34) is subjected to criticism and shown that, in contrast to Berljand's boundary condition, deposition means loss and not vice versa. In order to be able to judge in individual cases whether the second law of thermodynamics is fulfilled or not, the derivations (23) and (35) for the calculation of the concentration gradients are given.

\section{Sedimentation without deposition}

In the case of the reference solution for"sedimentation without deposition", if it is considered correctly, it is first shown that the task according to Fig. 2 is reduced to a trivial task and solution due to "volume source over the entire computing area", Eq. (40). The results for stationary and non-stationary calculations are shown in Fig. 3. The mass conservation law and the II. Law of thermodynamics are fulfilled in the case of a non-stationary calculation according to Eqs. (41) and (42) and in the case of a 
stationary solution according to Eqs. (45) and (46). The course of the solution according to Fig. 3 is comparable to filling any container with different media and cannot be related to tasks for modeling the spread of air pollutants. The stationary state is reached after filling according to $1 h$ and not only after 10Tagen, as the AUSTAL authors claim.

In the event of a faulty reference solution by the AUSTAL authors, there is no calculation equation available for stationary considerations due to Janicke's Convention and an indefinite expression for calculating the soil concentration. The pollutant particles in the control volume must be redistributed against the existing potential gradient so that they follow the faulty exponential function (48). The soil concentration is speculatively calculated using Eq. (49). In individual cases, Eq. (52) is used to prove that the mass conservation law has been violated. The conductive material flow is directed into the free atmosphere according to Eq. (53), whereas deposition flows point towards the bottom. The second law of thermodynamics is violated. The incorrect concentration curve is shown in Fig. 4. Despite a stationary observation, the AUSTAL authors questionably state the time-dependent simulation results. The stationary solution would have been reached after 10Tagen, and a time series over 10Tage would have been calculated, which is not true. The information on non-stationary solutions can only presumably be described as inventions by the authors of AUSTAL. The differential Eq. (3) is available for determining stationary solutions. But it is ignored.

\section{Deposition with sedimentation}

For the spreading case "Deposition with sedimentation" according to Fig. 5 of the task, correct consideration is initially assumed. The differential Eq. (2) is available for non-stationary calculations. The emission source is at an altitude of $200 \mathrm{~m}$. No analytical solution is available to solve this differential equation, which is why a numerical algorithm must be used. The method used here is based on the intermediate step method according to Janenko (1968), which was further developed in Schenk (1980) for tasks related to the spread of air pollutants. The results of this non-stationary calculation are shown in Fig. 6, Graphs A and B. The graphic A describes the nonstationary course of the propagation, and the graphic $B$ shows calculated integrals. They are required for proof of the validity of the main and maintenance rates. The stationary final state is reached after $2,6 h$ and not only after 10Tagen, as the AUSTAL authors claim. The conservation of mass is fulfilled according to Eq. (59). The deposition current coincides with the conductive material flow and is directed into the soil according to Eq. (60). The second law of thermodynamics is fulfilled. The stationary view is shown in graphic $\mathrm{C}$ in Fig. 6. A comparison between the graphs $\mathrm{A}$ and $\mathrm{C}$ shows an excellent agreement between numerical and analytical calculations for the stationary final states. The effect of high-altitude sources can be clearly seen in both non-stationary and stationary cases.

In the case of incorrect reference solutions by the AUSTAL authors, Eq. (64) proves that the mass conservation law is violated. According to Eq. (66) there is no conductive material flow, whereas the AUSTAL authors calculate an alleged deposition flow. The conductive material flow and the deposition flow are not identical, which is why the second law of thermodynamics is also violated here. The results of the AUSTAL authors are shown in Fig. 7. It cannot be seen that the authors of AUSTAL considered a source in $200 \mathrm{~m}$. The AUSTAL authors also report non-stationary simulation results for this spreading case. The steady state would also have occurred here according to 10Tagen, but this could not be confirmed. Time series were also not calculated. This information can also only be described as the idiosyncrasies of the AUSTAL authors. You lose all credibility.

\section{Homogeneity}

In addition to the sedimentation and deposition studies, four so-called homogeneity tests are also carried out. The tasks are described in Fig. 8 with graphics A to D. These are the test cases so-called, "Homogeneous turbulence, constant time step", so-called "Homogeneous turbulence, variable time step", so-called "Inhomogeneous turbulence, constant time step" and so-called "Inhomogeneous turbulence, variable time step". The wording of all these tasks is identical. The only difference is that in the case of so-called homogeneous turbulence, a constant effective mass transfer coefficient according to Eq. (68) and in the case of so-called inhomogeneous turbulence, a variable effective mass transfer coefficient according to Eq. (71) is used. Process engineering homogenization is confused with Fick's diffusion. While in the case of homogenization the concentration balance is brought about by an energy input, such as with stirring, in the case of diffusion an existing potential gradient is responsible for the concentration balance, which the AUSTAL authors do not understand. All tasks assume a "volume source distributed over the entire computing area". This assumption can be used to prove with Eqs. (40) and (73) that all the tasks for this can be traced back to a single trivial dispersion calculation with the solution (4). However, this only describes the filling of different containers with different media. It is a zero-dimensional spread with the time coordinate as the only independent variable. The simulation results are applicable for all dispersion cases, as can be seen in Fig. 9. 
With the end of the emission after the filling is completed and the steady state is reached. In contrast, the authors of Fig. 10 use graphics A to D to provide four different solutions for one and the same task. For the discernible filigree differences in the solution behavior, the authors of AUSTAL give detailed physical reasons and prove that they actually started from different solutions. They explain these deviations incomprehensibly, for example, with periodic edges or different force effects that would allegedly have an effect in the study area. The AUSTAL authors also do not recognize that all solutions have to be independent of any material parameters. They explain their results with drift speeds, which are not available. It was not recognized that all solutions should actually describe identical concentration courses. The lack of knowledge of the AUSTAL authors is convincingly demonstrated in this example. Here, too, the AUSTAL authors report non-stationary simulation results for all four propagation cases. The stationary final states would have returned after. It is also reiterated that a time series had been calculated. Not a single simulation result is true.

All of the tasks described for sedimentation, deposition and homogeneity have in common that they start from a three-dimensional investigation area. However, the differential Eq. (3) used by the AUSTAL authors only describes a one-dimensional propagation process. The reader is misled. All solutions and algorithms given by the authors of AUSTAL are wrong. Your train of thought cannot be understood with mathematics and mechanics. Confusion is created with determination.

\section{The analogy of the impulse, - heat and mass transport}

Textbooks on physics, thermodynamics and process engineering like to refer to the existing analogy to the impulse heat and mass transport. Looking at this analogy, the authors of AUSTAL would have to say, for example, that heat and material can be transferred from a lower energy level to a higher one. Because of the contradictions between tension and deformation, Newton's 3rd axiom would not be valid either. All principles of mathematics and mechanics are questioned with AUSTAL. The AUSTAL authors have to explain how you can recalculate nature experiments with dispersion models that contradict all recognized principles.

\section{Life stories}

The real life story is a prime example of how truths could be suppressed for 36 years. In contrast, the history of science in all disciplines proves that truths cannot be suppressed in the long run. The elitist life story is a teaching example of how to mislead the public for more than 36 years from 1984 to 2020 .

\section{Conclusion}

A prologue proves that AUSTAL is not validated. The simulation results for the reference solutions are wrong without exception. An epilogue has not yet been written. The authors of AUSTAL have to demonstrate how nature experiments can be calculated using dispersion models that contradict all recognized principles. All hazard prevention plans, safety analyzes and immission forecasts that have been determined with AUSTAL must be checked. Court rulings are also affected.

\begin{abstract}
Abbreviations
A $\left[\mathrm{m}^{2}\right]$ : Control room area; $\mathrm{C}_{\mathrm{i}}\left[\mu \mathrm{g} / \mathrm{m}^{3}\right]$ : Special solution; $\mathrm{C}\left[\mu \mathrm{g} / \mathrm{m}^{3}\right]$ : Concentration; $\mathrm{C}_{\mathrm{T}}\left[\mu \mathrm{g} / \mathrm{m}^{3}\right]$ : Concentration deep soil; $\bar{C}\left[\mu \mathrm{g} / \mathrm{m}^{3}\right]$ : Medium concentration; $C_{h}\left[\mu \mathrm{g} / \mathrm{m}^{3}\right]$ : Concentration above limit; $C_{A n}\left[\mu \mathrm{g} / \mathrm{m}^{3}\right]$ : Analytical solution; $C_{A}[\mu \mathrm{g} /$ $\left.\mathrm{m}^{3}\right]$ : Initial concentration; $F_{c}\left[\mu \mathrm{g} / \mathrm{m}^{2} \mathrm{~S}\right]$ : Area source; $H[\mathrm{~m}]$ : Upper limit of the study area; $\mathrm{K}_{\mathrm{B}}\left[\mathrm{m}^{2} / \mathrm{s}\right]$ : Diffusion coefficient floor; $\mathrm{K}_{\mathrm{Zz}}\left[\mathrm{m}^{2} / \mathrm{s}\right]$ : Diffusion coefficient $z$ direction; $K\left[\mathrm{~m}^{2} / \mathrm{s}\right]$ : Diffusion coefficient atmosphere; $\mathrm{L}_{\mathrm{x}, \mathrm{y}, \mathrm{z}}[\mathrm{m}]$ : Extension of the study area; $\dot{\mathrm{m}}^{\mathrm{s}}\left[\mu \mathrm{g} / \mathrm{m}^{2} \mathrm{~S}\right]$ : Conductive material flow atmosphere; $\mathrm{N}[\mathrm{w} /$ $\left.\mathrm{m}^{2}\right]$ : Conductive material flow floor; $\dot{\mathrm{m}}^{\mathrm{s}}\left[\mu \mathrm{g} / \mathrm{m}^{2} \mathrm{~S}\right]$ : Sedimentation flow; $\dot{\mathrm{m}}_{\mathrm{z}}^{\mathrm{B}}[\mu \mathrm{g} /$

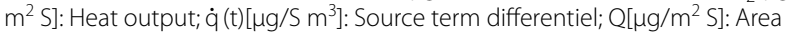
source; $t[\mathrm{~S}]$ : Time coordinate; $\mathrm{T}_{\mathrm{E}}[\mathrm{S}]$ : Time end simulation; $\mathrm{T}[\mathrm{m}]$ : Deep soil; $\mathrm{T}_{\mathrm{W}}[\mathrm{S}]$ : LAGRANGE correlation; $u[\mathrm{~m} / \mathrm{S}]$ : Speed; $\mathrm{V}_{\mathrm{ixxyz}}[\mathrm{m} / \mathrm{S}]$ : Speeds in spatial direction; $V_{s}[\mathrm{~m} / \mathrm{S}]$ : Sedimentation rate; $V_{d}[\mathrm{~m} / \mathrm{S}]$ : Deposition speed; $V_{d}^{\text {Schenk }}[\mathrm{m} / \mathrm{s}]$ : Deposition speed; $\bigvee^{\text {Janicke}}[\mathrm{m} / \mathrm{s}]$ : Deposition speed; $X_{i}^{*}[\mathrm{~m}]$ : Ground coordinate; $X_{i}[\mathrm{~m}]$ : Location coordinate; $Z[\mathrm{~m}]$ : Vertical coordinate; $\beta_{\mathrm{i}, \mathrm{Z}}[\mathrm{m} \mathrm{S}] \mathrm{]}$ : Mass transfer velocity; $\eta[\mathrm{kg} / \mathrm{m} \mathrm{S}]$ : Dynamic viscosity; $\vartheta[\mathrm{k}]$ : Temperature; $\lambda[\mathrm{w} / \mathrm{m} \mathrm{K}]$ : Thermal conductivity; $\varepsilon[\%]$ : Numerical error; $\sigma_{w}[\mathrm{~m} / \mathrm{S}]$ : Fluctuations in speed; $\tau\left[\mathrm{N} / \mathrm{m}^{2}\right]$ : Shear stress.
\end{abstract}

\section{Authors' information}

1968 doctorate to Dr.-Ing. at the Technical University of Merseburg. 1968-1970 additional studies in the field of "Computational Fluid Dynamics" at the Academy of Sciences of the former USSR in Novosibirsk, Akademgorodok. 1970 Lecturer in Theoretical Fluid Mechanics at the Technical University of Merseburg. Since 1972 active in the field of modeling of the spread of air pollutants at the Technical University of Merseburg and member of the main research area air pollution control at the Academy of Sciences of the former GDR. 1978 Calculation of transboundary pollutant flows and international cooperation with the Meteorological Institute of Leningrad University and with the NILU Institute Oslo. 1979 Calculation of long-distance transport Europe. 1979 Development of a $24 \mathrm{~h}$ forecast model and application by the Meteorological Service of the former GDR. 1980 Habilitation and scientific work in the field of numerical fluid mechanics and modeling of the spread of air pollutants under the direction of full members of the Academies of Sciences of the former USSR and former GDR Akademik JANENKO, Novosibirsk, and OM ALBRING, Dresden. 1980 participation in the construction of a data center east. 1980 Head of Environmental Monitoring at the Center for Environmental Design Wittenberg. 1982 Lecturer and University Professor of Fluid Mechanics at the Technical University of Zittau. 1985 Model for the calculation of the spread of radionuclides. 2004 honorary professor at the Technical University of Dresden, IHI Zittau. 1996 Research project model for the calculation of the spread of traffic emissions on behalf of the Ministry of the Environment Saxony-Anhalt. 2005 Research project model for the calculation of the expansion of heavy gases and vapors on behalf of the Ministry of the Environment of Saxony-Anhalt. 2007 Research project Mobile Environmental Data AVIS on behalf of the Arbeitsgemeinschaft für industrielle Forschung Berlin. 2008 Research Project Instruments Pollutant Prediction on behalf of the Arbeitsgemeinschaft für industrielle Forschung Berlin. 2010 Model for the calculation of the spread of traffic emissions taking into account moving point sources. 2015 Software developments for the evaluation of meteorological measurement series and for the development of cause analyzes.

\section{Acknowledgements}

The author thanks the meteorologist Dr.rer.nat. Klaus Schiller from the State Environment Agency of Saxony-Anhalt, Halle. He was a participant in the UBA 
workshops on the presentation of AUSTAL2000 on November 20, 2000 and on January 15 and March 28, 2001. After a thorough review and analysis, he was the first and only one of the participants in the workshop to recognize that all the graphics for spreading, sedimentation and deposition are wrong. He also recognized that the calculated concentration distributions cannot be used. Together, he and the author of this article asked the authors of the AUSTAL in Dunum for clarification. With the explanation that the engineering office Janicke from the Federal Environment Agency, Germany, was not only commissioned with the development but also with the quality assurance at the same time, any demand would be pointless. The author of this contribution continues to thank the environmental engineer Mr. Bergeassessor Dipl.-Ing. Peter Dolch from the company WESTKALK from Warstein. He asked the author of this article again for clarification because of the incomprehensible description of the spread, sedimentation and deposition by AUSTAL. This demand prompted the author of this article to take a closer look at the mathematics and physics of AUSTAL2000 from 2014. In this context, the author would also like to thank the company WESTKALK for the assignment to carry out the first "EXPERTISE ZU AUSTAL2000". Obviously not close enough to Dessau-Rosslau Dr.oec. Ursula Andrasch, MA, worked in the Wittenberg Center for Environmental Design. She graduated from the Leningrad Elite State University in Zhdanov, now St. Petersburg State University, and received her doctorate. The author of this publication thanks for their valuable contributions in the field of modeling propagation, sedimentation and deposition as well as the development of algorithms for the calculation of cross-border pollutant flows. The author of this article also thanks the process engineer Dr.-Ing. Ingwalt Friedemann, former Technical College Merseburg. He has proofread all AUSTAL2000 publications since 2014 and followed everything that happened with interest. Since 1972 he was also a member of the main research direction "Air pollution control" of the former GDR. Special thanks to the author of this contribution also go to Prof. Dr. rer.nat. habil. Prof. Ursula Stephan of the former Academy Institute for Chemical Toxicology in Leipzig. Your current job at the Hazardous Substances Office in Halle has shown the dangers to people and the environment if, for example, radioactive or toxic deposits are incorrectly calculated. The author of this publication also thanks the publisher of the German edition of the textbook Берлянд (1975), Prof. Dr.Ing.habil. Horst Ihlenfeld. For decades he was head of the wind tunnel at the Technical University of Dresden. The author of this article connects him with a fruitful scientific collaboration and personal friendship. He was also a member of the main research in keeping the air clean. Finally, the author thanks Mr. Alfred Trukenmüller from the Federal Environment Agency Dessau-Roßlau. His acquaintance has contributed greatly to the understanding of the AUSTAL dispersion model and its authors.

\section{Authors' contributions}

This entry was only published in "Environmental Systems Research". All authors read and approved the final manuscript.

\section{Funding}

There is self-financing

\section{Availability of data and materials}

Data and material are freely available.

\section{Ethics approval and consent to participate}

Permission to review this work by an ethics committee is granted.

\section{Consent for publication}

A publication of this work is approved.

\section{Competing interests}

".. as the responsible member of the Federal Environment Agency, I welcome and support constructive discussions about the TA Luft expansion model", is how Trukenmüller (2017) writes. The UBA will invite to a nationwide congress on the topic "Invite modeling and calculation of the spread of air pollutants". Until then you will spread silence rather than information.

\section{Author details}

${ }^{1}$ Present Address: 06193 Wettin-Löbejün, Germany. ${ }^{2}$ Dresden University of Technology, International University Institute Zittau, Zittau, Sachsen, Germany.
Received: 22 May 2020 Accepted: 11 August 2020

Published online: 16 October 2020

\section{References}

Abas N, Saleem MS, Kalair E (2019) Cooperative control of regional transboundary air pollutants. Environ Syst Res 8:10

Albring W (1961) Angewandte Strömungslehre. Akademie Verlag: Berlin

Axenfeld F, Janicke L, Münch J (1984) Entwicklung eines Modells zur Berechnung des Staubniederschlages. Umweltforschungsplan des Bundesministers des Innern Luftreinhaltung, Forschungsbericht 10402 562, Dornier System GmbH Friedrichshafen, im Auftrag des Umweltbundesamtes

BMU (2002) Erste Allgemeine Verwaltungsvorschrift zum Bundes-Immissionsschutzgesetz (Technische Anleitung zur Reinhaltung der Luft-TA Luft) Vom 24. Juli 2002. GMBL Heft 25-29 S: 511-605

Boŝnjakoviĉ F (1971) Techische Thermodynamik. Verlag Theodor und Steinkopf Dresden, 5. Auflage

Graedel TE, Crutzen PJ (1994) Chemie der Atmosphäre. Spektrum Akademischer Verlag, Heidelberg, Berlin, Oxford

Gröber, Erk, Grigull (1955) Grundgesetze der Wärmeübertragung. SpringerVerlag, Berlin, Göttingen, Heidelberg

Häfner F, Sames D, Voigt HD (1992) Wärme- und Stofftranspor. Springer-Verlag, Berlin, Heidelberg, New York, London, Paris, Tokyo, Hong Kong, Barcelona, Budapest

Janenko NN (1968) Die Zwischenschrittmethode zur Lösung mehrdimensionaler Probleme der mathematischen Physik. Springer-Verlag, Berlin

Janicke L (2000) IBJparticle Eine Implementierung des Ausbreitungsmodells. Bericht IBB Janicke, Dunum

Janicke (2001) Ausbreitungsmodell LASAT Referenzbuch zur Version 2.10. Dunum

Janicke (2002) AUSTAL 2000 Programmbeschreibung. Forschungskennzahl des Umweltbundesamtes UFOPLAN 20043 256, Dunum

Janicke L (2009) Ein Programmsystem LASAIR in der nuklearspezifischen Gefahrenabwehr, Vorhaben 3607504553 im Auftrag des Bundesministeriums für Umwelt, Naturschutz und Reaktorsicherheit. urn: nbn: de: 0221-2009011255, BfS- RESFOR-/06/09

Janicke L (2015) LASPORT Ein Programmsystem zur Berechnung von Emissionen und Immissionen flughafenbezogener Quellsysteme in der unteren Atmosphäre. Janicke Consulting, Dunum

Janicke U, Janicke L (2002) Entwicklung eines Modellgestützten Beurteilungssystems für den Anlagenbezogenen Immissionsschutz. IBJanicke Dunum

Janicke U, Janicke L (2011) AUSTAL2000 Stoffe nach TA Luft im Auftrag des Umweltbundesamtes Dessau-Roßlau, Geruchsausbreitung im Auftrag der Landesanstalt für Umweltschutz Karlsruhe, des Niedersächsischen Landesamtes für Ökologie Hildesheim und des Landesamtes NRW Essen. IB Janicke, Überlingen

Janicke U, Janicke L (2017) Genaue numerische Lösung und analytische Näherung für das Windprofil über ebenem Gelände. Berichte zur Umweltphysik, Number 8 S. 1-19

Kneschke A (1968) Differentialgleichungen und Randwertprobleme. Teubner Verlagsgesellschaft, Leipzig

Naue G (1967) Einführung in die Strömungsmechanik Vorlesung an der Technischen Hochschule Leuna-Merseburg. VEB Reprocolor Leipzig, Werk III/18/6 Nr. 3162/67

Pasquill F (1962) Atmospheric diffusion: The dispersion of windborne material from industrial and other sources. London van Nostrand

Rafique M, Nawaz H, Rafique H, Shahid M (2019) Material and method selection for efficient solid oxide fuel cell anode: recent advancements and reviews. Int J Energy Res 43(7):2423-2446

Schenk R (1979) Ein Modell zur Berechnung des grenzüberschreitenden Schadstofftransports. Konferenzmaterial der ehem. DDR zum Umweltschutzkongress auf hoher Ebene in Genf S: 11-22

Schenk R (1980) Numerische Behandlung nichtstationärer Transportprobleme. Habilitation, TU Dresden

Schenk R (2014) Expertise zu Austal 2000. Bericht im Auftrag der Vereinigten Warsteiner Kalksteinindustrie, Archiv Westkalk und IBS

Schenk R (2015a) AUSTAL2000 ist nicht validiert. Immissionsschutz $01.15 \mathrm{~S}$ : $10-21$ 
Schenk R (2015b) Replik auf den Beitrag „Erwiderung der Kritik von Schenk an AUSTAL2000 in Immissionsschutz 01/2015". Immissionsschutz 04.15 S. p. 189-191

Schenk R (2017) The pollutant spreading model AUSTAL2000 Is Not Validated. Environ Ecol Res 5(1):45-58

Schenk R (2018a) Not Only AUSTAL2000 is Not Validated. Environ Ecol Res 6(3):187-202

Schenk R (2018b) Deposition Mans Storage And Not Loss. Environmental Systems Research16. p: 1-14

Schenk R., Andrasch U. (1989) Numerische Simulation von Schadstofftransportvorgängen durch Lösung der Transportgleichung. Zeitschrift für Meteorologie, 30(1989)3 S: 169-175

Schlichting H (1964) Grenzschicht -Theorie. Verlag G, Braun Karlsruhe

Schorling M (2009) WinKFZ Verifikation nach VDI 3945. Ingenieurbüro Schorling \& Partner, Vagen

Schüle W (1930) Technische Thermodynamik. Verlag von Julius Springer, Berlin Simpson D, Benedictow A, Berge $H$, Bergström R, Emberson LD, Fagerli $H$, Flechard CR, Hayman GD, Gauss M, Jonson JE, Jenkin ME, Hyiri A, Richter C, Semeena VS, Tsyro S, Tuovinen JP, Valdebenito A, Wind P (2012) The EMEP MSC-W chemical transport model-techical description. Atmos Chem Phys 12:7825-7865

Stephan K, Mayinger F (1992) Thermodynamik, Grundlagen und Technische Anwendungen. Berlin, Heidelberg, New York, London, Paris, Tokyo, Hong Kong, Barcelona, Budapest, 13. Auflage

Travnikov O, Ilyin I (2005) Regional Model MSCE-HM of Heavy Metal Transboundary Air Pollution in Europe. EMEP/MSC-E Technical Report 6/2005

Truckenbrodt E (1983) Lehrbuch der angewandten Fluidmechanik. SpringerVerlag, Berlin, Heidelberg, New York, Tokyo

Trukenmüller A (2016) Äquivalenz der Referenzlösungen von Schenk und Janicke. Abhandlung Umweltbundesamt Dessau-Rosslau S: 1-5
Trukenmüller A (2017) Abhandlungen des Umweltbundesamtes vom 10.02.2017 und 23.03.2017. Dessau-Rosslau S: 1-15

Trukenmüller A, Bächlin W, Bahmann W, Förster A, Hartmann U, Hebbinghaus H, Janicke U, Müller WJ, Nielinger J, Petrich R, Schmonsees N, Strotkötter U, Wohlfahrt T, Wurzler S (2015) Erwiderung der Kritik von Schenk an AUSTAL2000 in Immissionsschutz 01/2015. Immissionsschutz 03/2015 S: 114-126

UBA (2015a) https://www.umweltbundesamt.de/themen/luft/regelungen - strategien/ausbreitungsmodelle-fuer-anlagenbezogene/faq\#textpart-1

UBA (2015) https://www.umweltbundesamt.de/themen/luft/regelungen-trate gien/ausbreitungsmodelle-fuer-anlagenbezogene/faq\#a13-wie-ist-diekritik-von-r-chenk-in-quotimmissionsschutzquot-012015-zu-bewerten

UBA (2018) https://www.umweltbundesamt.de/themen/luft/regelungen-trate gien/ausbreitungsmodelle-fuer-anlagenbezogene/uebersicht-gesch ichte

VDI Kommission Reinhaltung der Luft (1988) Stadtklima und Luftreinhaltung. Springer Verlag

VDI 3945 Blatt3 (2000) Umweltmeteorologie-Atmosphärisches Ausbreitungsmodell_-Partikelmodell. Beuth Verlag Berlin

Venkatram A, Pleim J (1999) The electrical analogy does not apply to modeling dry deposition of particles. Atmos Environ 33:3075-3076

Westphal WH (1959) Physik. Springer-Verlag Berlin, Göttingen, Heidelberg. 20. und 21. Auflage

Берлянд ME (1975) Современные проблемы диффузии и загрязнения атмосферы. Издательство Гидрометеоиздат

\section{Publisher's Note}

Springer Nature remains neutral with regard to jurisdictional claims in published maps and institutional affiliations.

\section{Submit your manuscript to a SpringerOpen ${ }^{\circ}$ journal and benefit from:}

- Convenient online submission

- Rigorous peer review

- Open access: articles freely available online

- High visibility within the field

- Retaining the copyright to your article

Submit your next manuscript at $\boldsymbol{\nabla}$ springeropen.com 